\title{
Behavioural, Histopathological, Genetic and Organism-Wide Responses to Phenanthrene- Induced Oxidative Stress in Eisenia Fetida Earthworms in Natural Soil Microcosms
}

\author{
Falin He \\ Shandong University \\ Hanmei Yu \\ Shandong University \\ Huijian Shi \\ Shandong University \\ Xiangxiang Li \\ Shandong University \\ Shanshan Chu \\ Shandong University \\ Chengqian Huo \\ Shandong University \\ Rutao Liu ( $\nabla$ rutaoliu@sdu.edu.cn ) \\ Shandong University
}

\section{Research Article}

Keywords: Phenanthrene, Eisenia fetida, Integrated biomarker response, Histopathology, oxidative stress, DNA damage

Posted Date: November 17th, 2021

DOI: https://doi.org/10.21203/rs.3.rs-1011942/v1

License: (c) (1) This work is licensed under a Creative Commons Attribution 4.0 International License. Read Full License 


\section{Abstract}

Phenanthrene (PHE) contamination not only changes the quality of soil environment but also threatens to the soil organisms. There is lack of focus on the eco-toxicity potential of contaminants in real soil in the current investigation. Here, we assessed the toxic effects of PHE on earthworms (Eisenia fetida) in natural soil matrix. PHE exhibited a relatively high toxicity to $E$. fetida in natural soil, with the $\mathrm{LC}_{50}$ determined to be $56.68 \mathrm{mg} \mathrm{kg}^{-1}$ after a 14-day exposure. Excessive ROS induced by PHE, leading to oxidative damage to biomacromolecules in E. fetida, including lipid peroxidation, protein carbonylation, and DNA damage. The antioxidant defense system (total antioxidant capacity, glutathione S-transferase, peroxidase, catalase, carboxylesterase, and superoxide dismutase) in E. fetida responded quickly to scavenge excess ROS and free radicals. Exposure to PHE resulted in earthworm avoidance responses (2.5 $\left.\mathrm{mg} \mathrm{kg}^{-1}\right)$ and habitat function loss $\left(10 \mathrm{mg} \mathrm{kg}^{-1}\right)$. Histological observations indicated that the intestine, body wall, and seminal vesicle in E. fetida were severely damaged after exposure to high-dose PHE. Moreover, earthworm growth (weight change) and reproduction (cocoon production and the number of juvenile) were also inhibited after exposure to this pollutant. Furthermore, the integrated toxicity of PHE toward E. fetida at different doses and exposure times was assessed by the integrated biomarker response (IBR), which confirm that PHE is more toxic to earthworms in the high-dose and long-term exposure groups. Our results showed that PHE exposure induced oxidative stress, disturbed antioxidant defense system, and caused oxidative damage in E. fetida. These effects can trigger behavior changes and damaged histological structure, finally cause growth inhibition, genotoxicity, and reproductive toxicity in earthworms. The strength of this study is the comprehensive toxicity evaluation of PHE to earthworms and highlights the need to investigate the t eco-toxicity potential of exogenous environmental pollutants in a real soil environment.

\section{Introduction}

Polycyclic aromatic hydrocarbons (PAHs) are made up of more than two fused aromatic rings in a linear or clustered arrangement (Eom et al. 2007; Gan et al. 2009; Achten and Andersson 2015). PAHs are class of hazardous chemicals, which are of great concern because of their carcinogenicity, teratogenicity, mutagenicity and toxicity properties (Elyamine and Hu 2020; Tomasetig et al. 2020). These chemicals are generated mainly from the incomplete pyrolysis of combustion of organic material such as coal, wood, and petroleum (Wilcke 2007; Maletić et al. 2019). In addition, accidental leakage of petroleum hydrocarbons during the exploration, transportation, production, refining, and storage also produce a large amount of PAHs (Wang et al. 2010; Chikere et al. 2012). Both the European Union (EU) and US EPA have identified sixteen representatives of PAHs as priority pollutants (Dimashki et al. 2001; Ma et al. 2015). Apart from the potential risks posed to human and animal health, potential risks are also posed to the environment, including atmosphere, soil, and water (Rubio-Clemente et al. 2014; Maletić et al. 2019).

Soil is the primary environmental sink for various contaminants since these chemicals can enter into the soil through both dry and wet deposition when they are emitted into the atmosphere (Chi 2014; Jia et al. 2017). Among the studies found, the soil has been polluted by polycyclic aromatic hydrocarbons in many 
countries (Johnsen et al. 2005; Fida et al. 2012). PAHs have highly stable chemical structures and long half-lives, so they are highly difficult to degrade in the soil (Ping et al. 2007; Chen et al. 2013). High concentrations of $\sum_{16} \mathrm{PAHs}$ were found in Chinese surface soil ranged from 9.90 to $5911 \mathrm{\mu g} \mathrm{kg}^{-1}$, especially riverbank soil exhibited a higher level (Ma et al. 2015; Deng and Zeng 2017). More importantly, PAHs exist in the soil inevitably have a significant impact on terrestrial environments (Wu et al. 2012b; He et al. 2021a).

Hydrocarbons are more likely to aggregate and accumulate in the pores among soil particles. This leads to the decrease of soil permeability to oxygen and water, resulting in the reduction of soil quality (Osuji et al. 2006). The toxicity and bioavailability of pollutants such as PAHs in soil are affected by soil types and soil properties (Duan et al. 2016). Previous studies have found that soil particle size could affect the distribution and accumulation of pollutants in soil, and PAHs prefer to accumulate in fine soil particles (Wang et al. 2020). Other factors (e.g., soil organic matter content, soil pH, soil particle size, and soil microbial activities) can also influence the degradation of environmental contaminants such as heavy metals and PAHs in soil (Askari et al. 2020; Xu et al. 2021). Therefore, the soil types and soil properties should be considered in ecological risk assessment and soil environmental quality standards establishment (Duan et al. 2016; Zhu et al. 2020).

Phenanthrene (PHE, structure shown in Fig. S1) is one of the most abundant low-molecular-weight PAHs, which is widespread in the environment. It is estimated that annually about 29,190 tons of phenanthrene are released into the environment (He et al. 2021a). Exposure to and toxicity from PHE has been reported in human and aquatic organisms (Hong et al. 2017). Moreover, PHE exhibited potential threats to soil invertebrates such as earthworms (Andreoni et al. 2004; Picariello et al. 2020; He et al. 2021a). The LC 50 value for E. fetida ranged between 31.47 to $281 \mathrm{mg} \mathrm{kg}^{-1}$ after 14 exposure to PHE. The difference in PHE toxicity to earthworms is evident in response to soil types and assay methods. Zhu et al. (2020) reported that the toxicity of toxic substances to soil invertebrates could be influenced by soil physicochemical properties. Hence, soil characteristics are one of the main factors affecting the toxicity of multiple exogenous environmental pollutants to soil organisms.

Previous studies have only focused on the toxic effects of numerous environmental pollutants on earthworms in artificial OECD soil, with few studies reporting on their toxicity potential in a real soil environment. In this study, the acute toxicity of PHE toward earthworm Eisenia fetida was first evaluated in natural soil medium. We further evaluated the effects of PHE exposure on the behavior, growth, and reproduction of $E$. fetida. In addition, the histopathological examination was also performed to assess the tissue damage of PHE to the intestine, body wall, and seminal vesicle of adult $E$. fetida. To comprehensively compare the toxic effects of PHE to E. fetida at different doses and exposure times, a series of biomarkers including the ROS level, oxidative damage degree, and antioxidant enzyme activity changes induced by PHE were chosen to calculate the integrated biomarker response (IBR) index. The purpose of this study is to elucidate the importance of soil types when evaluating PHE toxicity in multicontaminated soil ecosystems and provide a valuable reference for assessing the ecological risks of toxic xenobiotics, including PAHs in a real soil environment. 


\section{Materials And Methods \\ Chemicals and reagents}

Phenanthrene of $99.5 \%$ purity was purchased from Sigma-Aldrich (St. Louis, MO, USA). All reagents (analytically pure) were acquired from Sinopharm Chemical Reagent Co., Ltd. (Beijing, China) and Tianjin Kaitong Chemical Reagent Co. Ltd. (Tianjin, China). The Kits used in this study were acquired from Nanjing Jiancheng Bioengineering Institute (Nanjing, China) and Beijing Solarbio Science \& Technology Co., Ltd. (Beijing, China). Moreover, ultrapure water $(18.25 \mathrm{M} \Omega \mathrm{cm})$ was used for all of the experiments.

\section{Test organisms and soil}

The tested natural soil without any contamination was collected from Shandong University experimental fields (Qingdao, China) (36.36 N, 120.68 E). Then, the soil was air-dried, and sieved with a $10 \mathrm{~mm}$ mesh sieve to remove pebbles and coarse fragments. The moisture content of the tested soil was controlled at $30 \%$ throughout the experiments. The physicochemical properties of tested soils were exhibited in Table S1. No PAHs were detected in the tested soils.

Earthworms (Eisenia fetida) were purchased from Shandong Agricultural University (Taian, China). The tested earthworms were incubated in the laboratory at $20 \pm 1{ }^{\circ} \mathrm{C}$, with humidity varying between 70 and $80 \%$, and a $12: 12 \mathrm{~h}(\mathrm{~L}: \mathrm{D})$ photoperiod for at least 14 days. Healthy mature adult earthworms with welldeveloped clitella and similar body weight (350-400 mg) were chosen for further experiments. Test earthworms were transferred in the tested natural soil described above in an artificial climate chamber, and pre-incubated for $24 \mathrm{~h}$ before exposure to phenanthrene.

\section{Acute toxicity test}

The acute toxicity of $E$. fetida was assessed in 1-L glass beakers (six replicates per concentration) with $500 \mathrm{~g}$ natural soil as described by the OECD Test Guideline (OECD 1984) with some modifications. A standard stock solution was prepared by dissolving $0.5025 \mathrm{~g}$ of PHE in $50 \mathrm{~mL}$ acetone at a concentration of $10000 \mathrm{mg} / \mathrm{L}$. The stock solution was diluted with acetone to give the required various PHE concentrations that were added with $500 \mathrm{~g}$ of the natural soil described above. Table S2 exhibits the acute exposure doses of PHE used in this study. The soil of each treatment was thoroughly mixed, and filled into 1-L beakers. All beakers were shifted to a well-vented fume hood to remove acetone for $12 \mathrm{~h}$.

Before exposure to PHE, the earthworms were rinsed with ultrapure water, and then placed on humid filter paper in Petri dishes for $24 \mathrm{~h}$ to promote the gut content excretion. Then, ten individuals were transferred to each beaker. Next, the beakers were covered using plastic film to limit the evaporation of water and prevent earthworm escape, and cultured at $20 \pm 1^{\circ} \mathrm{C}$ temperature, $75 \pm 5 \%$ relative humidity, and a photoperiod of $12: 12 \mathrm{~h}$. The same amount of acetone was established as the control. Earthworms were fed sterile cow manure at a dose of $0.50 \mathrm{~g}$ per individual per week. The number of surviving earthworms was checked and recorded at 7 and $14 \mathrm{~d}$ after PHE exposure.

\section{Avoidance test}


According to the acute toxicity test, Five PHE doses $\left(0,1.25,2.5,5\right.$, and $\left.10 \mathrm{mg} \mathrm{kg}^{-1}\right)$ were used to evaluate the avoidance behavior of adult $E$. fetida in natural soil medium. The avoidance test was conducted by the ISO 17512-1 standard (ISO 2008). Briefly, the beakers were divided into two sections by a partition. One-half of the beaker was filled with $300 \mathrm{~g}$ soil contaminated with PHE $\left(1.25,2.5,5\right.$, and $\left.10 \mathrm{mg} \mathrm{kg}^{-1}\right)$ (Section A), and the other half was added with the similar amount of untreated soil (Section B). Then, the partition was removed, and ten adult $E$. fetida were transferred to the central space of the beaker. The beakers were covered with a pored plastic film to a allow oxygenation and void earthworm escape. Then, they were cultured in a controlled climate chamber, and the rearing conditions were consistent with those mentioned above (Section 2.3). An equal volume of acetone was added as black control. Six replicates were conducted for each treatment group. After $48 \mathrm{~h}$ of exposure, the surviving individuals in each half of the container were counted. The avoidance response of each treatment was assessed via the following equation:

$N R=\frac{C-T}{N} \times 100 \%$

where $N R$ represents the net avoidance response (\%), $N$ represents the number of sum earthworms of each beaker, and $C$ and $T$ are earthworms in the control soil without PHE and in PHE-amended (treated) soil, respectively.

The avoidance response were classified by Equation (1) as described by ISO (2008): ( $\mathbb{~}$ ) no effect and/or no response $(N R<20 \%)$; ( () avoidance effect $(20 \% \leq N R \leq 80 \%)$; ( () habitat function loss $(N R>80 \%)$.

\section{Toxic effects on E. fetida following exposure to phenanthrene Preparation of earthworm samples}

Five PHE concentrations at $0,1.25,2.5,5$, and $10 \mathrm{mg} \mathrm{kg}^{-1}$ were selected for measuring the detoxification and antioxidant processes, oxidative damage degree, and genotoxicity on adult $E$. fetida. The exposure treatment protocol was similar to those described in the acute toxicity test (Section 2.3). After treatment, tested earthworms were cultured as described in Section 2.3. $5 \mathrm{~g}$ of sterile cow manure per earthworm per week was provided as food.

After 1, 3, 5, 7, and 14 days of exposure, the survival individuals were removed from beakers and rinsed with deionized water. To empty intestinal contents, the earthworms were incubated for $24 \mathrm{~h}$. Afterwards, the individuals were quickly frozen with liquid nitrogen, and earthworm samples were stored at $-80^{\circ} \mathrm{C}$ until analysis. Earthworm tissue samples were homogenated with phosphate buffer solution and then centrifuged at $2000 \mathrm{rpm}$ at $4^{\circ} \mathrm{C}$ for $15 \mathrm{~min}$. The supernatant was used for the following analyses (total protein content, malondialdehyde (MDA), total antioxidant capacity (TAC), peroxidase (POD), glutathione S-transferase (GST), catalase (CAT), carboxylesterase (CarE), and superoxide dismutase (SOD)).

\section{ROS level measurement}


DCFH-DA (2',7'-dichlorofluorescin diacetate) is a commonly used ROS fluorescent probe described previously (Lawler et al. 2003; Charan et al. 2020). DCFH-DA itself has no fluorescence that enters the internal cells and is hydrolyzed by esterases to DCFH, a non-fluorescent compound. Oxidation of DCFH produced strong green fluorescence in the presence of ROS. Therefore, DCF fluorescence intensity can reflect intracellular ROS levels in cells. Earthworm tissues were homogenized as described by Xu et al. (2021), and the fluorescence intensity was detected on a microplate reader (Spark, TECAN, Switzerland) using an emission of $525 \mathrm{~nm}$ and excitation of $485 \mathrm{~nm}$.

\section{Assessment of antioxidant enzyme activities}

The antioxidant enzyme activities (TAC, CarE, GST, POD, CAT, and SOD) in E. fetida were measured by the instructions of the Assay Kit. The total protein content in E. fetida was determined by the Bradford method (Bradford 1976). The detailed processes were described in the Supplementary Material.

\section{Determination of oxidative damage degree in E. fetida Lipid peroxidation determination}

Lipid peroxidation levels could be assayed by detecting the end product of lipid peroxidation, malonaldehyde (MDA), which can condense with thiobarbituric acid (TBA) to generate a red product that

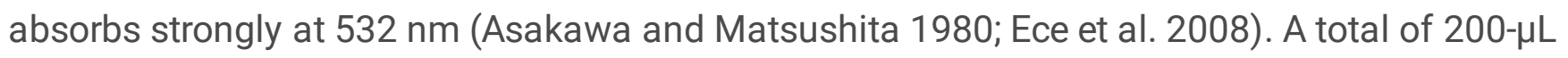
supernatant was used to detect the MDA content in E. fetida as per the instructions of the MDA Assay Kit. Absorbance at $532 \mathrm{~nm}$ was detected using a UV-2600 spectrophotometer (Shimadzu, Japan).

\section{Measurement of protein carbonylation (PCO)}

The PCO level was evaluated by a previously reported method (Luo and Wehr 2009; Liu et al. 2018). Carbonyl groups in proteins can react with 2,4-dinitrophenylhydrazine to produce protein-bound 2,4dinitrophenylhydrazones, which was detected spectrophotometrically at $370 \mathrm{~nm}$ using a UV-2600 spectrophotometer (Shimadzu, Japan) with quartz cuvettes (0.5-cm path length). Earthworm tissue homogenates and experimental processes were conducted by the instructions of the PCO Assay Kit.

\section{Determination of DNA damage of E. fetida coelomocytes 8-OHdG level determination}

The amount of 8-OHdG was measured by an enzyme-linked immunosorbent assay (ELISA) kit. Tissue samples were processed as per the constructions of the Assay Kit. A total of 50- $\mu \mathrm{L}$ supernatant was used to assess the 8-OHdG level in E. fetida. The values of absorbance at $450 \mathrm{~nm}$ were recorded on a microplate reader (Spark, TECAN, Switzerland). A standard curve was fitted using a four-parameter nonlinear logistic regression model with ELISAcalc software.

\section{Comet assay}

Comet assay was conducted to assess the degree of DNA damage in E. fetida coelomocytes (Song et al. 2009). Two survival earthworms were removed from each treatment to assess the DNA damage on days 
$1,3,5,7$, and 14 . Then, the earthworms were washed with ultrapure water and cultured for $24 \mathrm{~h}$. The coelomocytes were collected using an extracting solution ( $1 \mathrm{~g}$ guaifenesin, $0.25 \mathrm{~g}$ EDTA, $5 \%$ alcohol, and $0.9 \%$ normal saline) (Song et al. 2009; He et al. 2021a). The coelomocytes, including extracting solution, were centrifugated at $2000 \mathrm{rpm}$ for $5 \mathrm{~min}$. After centrifugation, the supernatant was discarded, and the coelomocytes were washed three times with normal saline.

The coelomocytes were mixed with low-melting agarose $(0.75 \%)$ and pipetted onto a microslide loaded with normal-melting agarose (NMA, 0.75\%). After the solidification, the cell lysis, DNA unwinding, electrophoresis, neutralization, and staining were realized by the methods of Song et al. (2009). Then, the comets were observed and captured with a Nikon Eclipse Ti-s fluorescence microscope (Nikon, Tokyo, Japan). At least 150 cells were analyzed per sample using the CASP software (CaspLab.com) (Końca et al. 2003).

\section{Measurement of weight change of E. fetida}

Five PHE doses $\left(0,1.25,2.5,5\right.$, and $\left.10 \mathrm{mg} \mathrm{kg}^{-1}\right)$ were chosen for assessing the weight change of adult $E$. fetida in natural soil. Earthworms and exposure conditions were prepared as described above (Section 2.3). Before the exposure to PHE, the weight of adult earthworms in each exposure group was weighed on an electronic analytical balance (Sartorius, BT125D) and recorded as $W_{0}$. At 7, 14, 21, and 28 days, the tested earthworms were weighed and recorded as $W_{t}$. The weight change was assessed via the following formula:

Weight change $(\%)=\frac{W_{t}-W_{0}}{W_{0}} \times 100 \%(2)$

\section{Assessment of reproductive toxicity of E. fetida}

Earthworms exposed to PHE as described in Section 2.6 for assessing the reproductive toxicity of juveniles produced by E. fetida in natural soil. Each week, the soil moisture of each beaker was checked and replenished by adding ultrapure water. Moreover, an appropriate amount of cow manure was added as food every week. On days 28 and 56 of the experiment, two soils contaminated with PHE in each treatment were sieved using a 1-mm mesh aperture and recorded the number of cocoons and juveniles.

\section{Microstructure of the intestine, body wall, and seminal vesicle of adult E. fetida}

For histopathological examination, four live earthworms were taken from each treatment after 28 days of exposure. The soil on the surface of earthworms was washed with ultrapure water. Then, the individuals were transferred in Petri dishes to depurate for $24 \mathrm{~h}$. After depuration, about $5 \mathrm{~mm}$ tissue of the seminal vesicle and intestine of individual earthworm was cut with a razor blade, and then soaked in formaldehyde for $48 \mathrm{~h}$. The fixed samples were dehydrated with ethanol, permeated with wax, and embedded in wax. Sections were sliced at a thickness of $10 \mathrm{~mm}$ and stained with hematoxylin and eosin 
$(H \& E)$. Finally, the microstructure of the intestine and seminal vesicle of earthworm was observed on a Nikon Eclipse Ci-L microscope (Nikon, Tokyo, Japan).

\section{Integrated biological response}

The integrated biomarker response v2 (IBRv2) (Sanchez et al. 2013) was used to assess the comprehensive toxic effects of PHE exposure at different doses and exposure times. In this study, a series of biomarkers including MDA, ROS, GST, CarE, POD, SOD, CAT, TAC, PCO, 8-OHdG, and OTM of E. fetida after PHE exposure on days 1, 3, 5, 7, and 14 were selected to calculate IBR index. The detailed procedure of IBRv2 calculation was described in Supplementary Materials.

\section{Data analysis}

Statistical differences of all data in this study were analyzed using one-way ANOVA followed by the least significant difference test $(P<0.05)$ by SPSS 26.0 (SPSS Inc., Chicago, IL, USA). The IBRv2 values were calculated using Microsoft Excel 2010. All figures were plotted using SigmaPlot 14.0 (Systat Sofware Inc., San Jose, CA, USA).

\section{Results And Discussion}

\section{Acute toxicity}

The results of acute toxicity (7-d and $14-\mathrm{d} \mathrm{LC}_{50}$ ) of PHE toward adult E. fetida in natural medium are exhibited in Table S3. In the control groups, the mortality rate during the test period of exposure was below 5\%. As shown in Table S3, PHE caused lethal toxicity at $103.41 \mathrm{mg} \mathrm{kg}^{-1}$ of the $\mathrm{LC}_{50}$ value after 7-d exposure. At the same time, Nam et al. (2017) reported that a higher mortality with $86.20 \mathrm{mg} \mathrm{kg}^{-1}$ of $\mathrm{LC}_{50}$ value in artificial soil after PHE exposure for $7 \mathrm{~d}$. The $\mathrm{LC}_{50}$ of $E$. fetida in natural soil after $14 \mathrm{~d}$ treatment with PHE was $56.68 \mathrm{mg} \mathrm{kg}^{-1}$ (Table S3), which was similar to that of measured values in the natural medium was $40.67 \mathrm{mg} \mathrm{kg}^{-1}$ (Wu et al. 2011). The difference in toxicity between different studies may be due to the types of food supply and the total water-holding capacity of tested soil during the trial period (Nam et al. 2015). Another reason might be the variance among individuals from different populations used. Importantly, we found that the earthworms did not get into the soil above $12.5 \mathrm{mg} \mathrm{kg}^{-1}$ of PHE exposure. More research should be conducted to reveal the relationships between PHE toxicity to earthworms and soil properties.

\section{Effects of phenanthrene on the ROS levels in adult E. fetida}

Reactive oxygen species produced in cells and contributed by a disruption of cellular redox balance (Song et al. 2009; Delmastro-Greenwood et al. 2014; Song et al. 2019). Moreover, ROS have been reported to be induced various biological effects, including cell growth, apoptosis, and protein activity, leading to substantial damage to cellular function, and even structure (Choudhury and Panda 2005; Shin et al. 2009). The intracellular amount of ROS is an important biomarker for oxidative stress, and the increased 
ROS levels can effectively reflect the level of oxidative stress (Song et al. 2009; Zhang et al. 2014). The changes of ROS levels in adult E. fetida when earthworms were treated with PHE at different time intervals are shown in Fig. 1.

As exhibited in Fig. 1, no significant difference was found between the groups exposed to a lower dose of PHE (1.25 mg kg$\left.{ }^{-1}\right)$ and the control group. However, in higher dose PHE-treated groups (2.5, 5, and $10 \mathrm{mg}$ $\mathrm{kg}^{-1}$ ), the ROS levels in adult E. fetida was dramatically induced compared to the control treatment on the first day after PHE exposure (Fig. 1). Compared to the control, the ROS levels in all PHE-treated groups (1.25-10 $\mathrm{mg} \mathrm{kg}^{-1}$ ) was observably induced than that of the control group on days $3,5,7$, and 14, and it increased with the PHE concentration, showing a clear dose-response relationship (Fig. 1). He et al. (2021a) also reported that the ROS levels in coelomocytes of $E$. fetida was significantly increased, showing a clear dose-effect relationship after 24-h exposure to phenanthrene. These results suggest that PHE exposure can damage the balance between elimination and production of ROS in cells, inducing an increased ROS production and accumulation of ROS-derived damages, eventually leading to oxidative stress in E. fetida.

\section{Antioxidant defense responses in adult E. fetida after phenanthrene exposure}

The antioxidant defense systems in living organisms can spontaneously eliminate ROS or repair damage induced by the action of oxidative stress to prevent irreversible cellular oxidative damage in normal physiological conditions (Sies 1997; Ece et al. 2008). When facing exogenous stress, various intracellular antioxidases, and small-molecule antioxidants (e.g., SOD, CAT, GST, and TAC) exist in E. fetida respond quickly to scavenge excess ROS and free radicals, and lessen cellular oxidative stress and associated cellular damage (Wu et al. 2011; He et al. 2021a). Of the antioxidant system, SOD and CAT provide the first line of defense against oxidative damage caused by excessive ROS in cells (Zhang et al. 2020).

SOD, identified as essential component in antioxidant defense system (El-Mas et al. 2012) that can effectively remove the intracellular oxygen free radicals $\left(\mathrm{O}_{2}{ }^{-}\right)$through decomposing them into molecular oxygen $\left(\mathrm{O}_{2}\right)$ and hydrogen peroxide $\left(\mathrm{H}_{2} \mathrm{O}_{2}\right)$ (Song et al. 2009; Liu et al. 2017). In this study, the SOD activities in earthworms were activated in all PHE-treated groups on days 1 and 3 (Fig. 2A). Increased SOD activity indicates that $E$. fetida has begun to retard the oxidative damage caused by PHE. The SOD activity in higher treated groups ( 5 and $10 \mathrm{mg} \mathrm{kg}^{-1}$ ) was inhibited beginning at day 5 until day 14 (Fig. 2A). The decrease in SOD activity may be attributed to the $\mathrm{O}_{2}{ }^{-}$level exceeding the eliminating ability of SOD under PHE stress, thereby inhibiting SOD activity.

However, $\mathrm{H}_{2} \mathrm{O}_{2}$ is similarly a kind of ROS, which has a strong ability to induce cell oxidative damage, and it can also stimulate ROS generation (Liu et al. 2017; He et al. 2021b). CAT is a specific $\mathrm{H}_{2} \mathrm{O}_{2}$ scavenger, which can remove the excess $\mathrm{H}_{2} \mathrm{O}_{2}$ by converting it into $\mathrm{O}_{2}$ and $\mathrm{H}_{2} \mathrm{O}$ (Wu et al. 2012a; Liu et al. 2018). In PHE amended soil, the CAT activity in earthworms showed an upward trend on the first day and third day (Fig. 2B). However, the activity of CAT begun to decrease as the time of exposure was extended (7 and 14 d) (Fig. 2B). According to the theory of ROS (Mittler 2002; Zhang et al. 2020), the increased CAT activity 
may be induced by external factors, which lead to an increase in the amount of ROS produced in earthworms, so the biosynthesis of CAT was significantly increased. The decrease of CAT activity may be due to PHE exposure increases the levels of oxidative stress, resulting in the removal rate of ROS lower than the production rate of ROS. Another reason may be that the enzyme superoxide dismutase in cells converts $\mathrm{O}_{2}^{-}$into $\mathrm{H}_{2} \mathrm{O}_{2}$, and excessive $\mathrm{H}_{2} \mathrm{O}_{2}$ can inhibit the activity of CAT (Zhang et al. 2021).

As another important antioxidant enzyme, POD involves in the defense mechanism against exogenous stresses by removing the excess $\mathrm{H}_{2} \mathrm{O}_{2}$ in cells (Song et al. 2009; Zhang et al. 2014). Fig. $2 \mathrm{C}$ exhibits that the POD activity in adult $E$. fetida after PHE exposure at different time intervals. In all PHE-treated groups, the POD activity in earthworms was activated compared to the control. It increased with the PHE dose and the treatment time, showing a clear dose-response relationship (Fig. 2C). The enhanced POD activity may be that the oxidative stress to $E$. fetida increases with increasing PHE concentration, and POD assists CAT to eliminate excess $\mathrm{H}_{2} \mathrm{O}_{2}$ in earthworms under PHE stress (Qiao et al. 2019).

GST is the most important phase II detoxifying metabolic enzyme in cells (Saint-Denis et al. 1998; Liu et al. 2017) that can remove ROS caused by oxidative stress through accelerating the combination of ROS with electrophilic reagents and glutathione to metabolize contaminants (Pickett and Lu 1989). Besides that, GST can also eliminate the lipid peroxidation metabolites such as malondialdehyde and reduce DNA damage in organisms (Song et al. 2019; Yao et al. 2020; 2021). The enzymatic activities of GST in adult E. fetida exposed to PHE at various time intervals are shown in Fig. 2D. As illustrated in Fig. 2D, no significant difference was observed between PHE-treated groups and the control group at 1st day. Comprehensive results showed that the activity of GST in earthworms increased at early periods of exposure ( 3 and $5 \mathrm{~d}$ ) and then decreased after treatment with different doses of phenanthrene on days 7 and 14 (Fig. 2D). This finding indicates that the increased GST activity was needed to effectively detoxify the PHE-induced ROS and oxidative damage to reduce the toxicity of harmful compounds against earthworms. The deceased GST activity may be due to the excessive ROS and free radicals induced by PHE beyond the normal detoxification or repair capacities in earthworms.

CarE, an enzyme responsible for the detoxification of exogenous toxicants, which is involved in xenobiotic metabolisms in organisms (Wang et al. 2019). Additionally, previous studies have reported that the CarE activity in earthworms shows the slowest recovery rate among other organisms (Collange et al. 2010; Ečimović et al. 2019). Hence, CarE is an excellent biomarker for assessing the environmental impacts of pollutants. The activity of CarE in adult E. fetida after exposure to PHE in natural soil medium is presented in Fig. 2E. The CarE activity in E. fetida in treatment groups exposed to PHE was not significantly different from that in the control group on 1st day (Fig. 2E). In the higher dose treatment groups ( 5 and $10 \mathrm{mg} \mathrm{kg}^{-1}$ ), the CarE activity in earthworms was significantly activated compared to the control on days 3 and 5. In addition, the CarE activity in E. fetida of all PHE-treated groups was observably lower than that in the untreated group, and it decreased with the PHE dose, exhibiting a clear dose-response relationship (Fig. 2E). This result shows that exposure to PHE can inhibit the activity of 
CarE, resulting in the detoxification function in E. fetida was impaired, especially in the high-dose and long-time exposure.

Total antioxidant capacity (TAC) including non-enzymatic antioxidant defense systems and antioxidant enzymes that can supply a comprehensive antioxidant assessment (Sies 1997; Meng et al. 2019). Its levels are considered a key evaluation index that reflects the scavenging capacity of free radicals and ROS in living organisms (Chen et al. 2015; Hu et al. 2019). The T-AOC levels in adult E. fetida after exposure to PHE in natural soil soil are exhibited in Fig. 2F.

As indicated in Fig. 2F, the T-AOC levels in earthworms were higher in all PHE-treated groups at all time points, except for a lower dose treatment group $\left(1.25 \mathrm{mg} \mathrm{kg}^{-1}\right)$ on $1 \mathrm{st}$ day in the natural medium. The increase in the total antioxidant capacity indicated that $E$. fetida have begun to remove damage caused by PHE pressure. However, a decreased tendency of the TAC levels in E. fetida was observed at a high concentration $\left(10 \mathrm{mg} \mathrm{kg}^{-1}\right)$ on the last day (14 d) of PHE exposure. This result indicated that the antioxidant system in E. fetida could not completely counteract the oxidative stress induced by PHE, and increased ROS can lead to oxidative damage to E. fetida, especially exposure at higher doses and longer times.

\section{Effects of phenanthrene on the degree of oxidative damage in adult E. fetida}

Upon exposure to exogenous stress, the production of ROS in cells is an inevitable process (Song et al. 2009). Meanwhile, the endogenous antioxidant system in cells is not sufficient to remove excess ROS under most oxidative stress conditions (Sies 1997; Jiang et al. 2020). The accumulation of excess ROS can result in oxidative damage to macromolecules, such as lipids, proteins, and DNA, thus accelerating the development of LPO, protein carbonylation, and DNA damage, ultimately trigger cell death (Wu et al. 2012b; Liu et al. 2017).

Malondialdehyde (MDA) is known as the cell membrane lipid peroxidation end-products, which is widely considered as an oxidative stress indicator in cells (Song et al. 2009; Zhu et al. 2020). Also, its contents can indirectly reflect the damage level of LPO and cell membranes (Qiao et al. 2019). The changes in MDA content in E. fetida exposed to PHE in natural soil matrix are exhibited in Fig. 3A. Similar to the ROS results, the MDA levels in E. fetida was beyond the normal levels in all PHE exposure treatments throughout the exposure trial period. Moreover, the MDA content was greatly enhanced as the concentration of PHE increased, showing an explicit dose-response relationship (Fig. 3A). The increased MDA content indicated that PHE exposure could induce more ROS in E. fetida and cause LPO and oxidative damage to earthworms. Previously, He et al. (2021a) also reported that PHE exposure can induce lipid peroxidation in coelomocytes of E. fetida. These findings indicate that PHE could trigger oxidative damage to cell membranes in adult $E$. fetida, especially at high concentration levels.

Protein carbonylation is an irreversible and non-enzymatic post-translational modification induced by excess ROS, which can cause a change of protein structure, make it lose its original biological function (Weng et al. 2017). The PCO level is widely used as a marker of oxidative damage in proteins (England et 
al. 2006; Liu et al. 2018). No significant change in PCO content on 1st day for lower concentrations (1.25 and $2.5 \mathrm{mg} \mathrm{kg}^{-1}$ ) of PHE compared to the control (Fig. 3B). However, a significant increase in PCO content in E. fetida was found in 5 and $10 \mathrm{mg} \mathrm{kg}^{-1}$ treatment groups on days 3, 5, 7, and 14 compared to the control (Fig. 3B). These findings show that environmental contaminants, including PHE, can cause oxidative damage to the protein in E. fetida.

\section{Coelomocyte DNA damage in E. fetida exposed to phenanthrene}

DNA damage is one of the most harmful toxic effects of exogenous toxicants. One target of reactive oxygen species is DNA, which is more vulnerable to oxidative stress in organisms (Turillazzi et al. 2017; Song et al. 2019). 8-hyoxy-2-deoxyguanosine (8-OHdG) is the product of the 8th carbon atom of guanine base in DNA molecules frequently attacked by ROS (e.g., hydroxyl radicals and singlet oxygen) (Agnihotri and Mishra 2009; Xu et al. 2021). Accordingly, the 8-OHdG level is regarded as a promising indicator to evaluate the degree of oxidative stress and DNA damage of endogenous and exogenous factors to earthworms (Zhang et al. 2020; Zhu et al. 2020). In this study, the level of DNA oxidative damage was determined by measuring the content of $8-\mathrm{OHdG}$ in adult $\mathrm{E}$. fetida. The results showed that the 8-OHdG level in E. fetida all PHE-treated groups was significantly induced compared to the control (Fig. $3 \mathrm{C}$ ). This result demonstrated that PHE could cause DNA oxidative damage to coelomocytes of E. fetida. This result indicates that PHE exposure can cause oxidative stress in E. fetida, and finally result in DNA damage.

The comet assay is a simple and rapid method for detecting the DNA damage and repair at the individual-cell level (Song et al. 2009; Gajski et al. 2019). In the control group, the nuclear DNA aggregated into a dense round shape, with little or no DNA migrating to the periphery (Fig. 3F1). The comet head of coelomocytes appeared fluffy, mushy, and scattered, and longer comet tails were observed when the $E$. fetida earthworms were exposed to high-dose PHE (Fig. 3F2 and F3). Several studies have demonstrated that a good linear relationship between the OTM value and DNA damage (Olive et al. 2012; Song et al. 2019). Thus, the value of OTM can be used to quantitatively evaluate the DNA damage in organisms after exposure to exogenous contaminants. In this study, the degree of DNA damage of coelomocytes in E. fetida after PHE exposure at different doses and various time intervals was assessed in natural soil. As exhibited in Fig. 3D, the OTM value in lower PHE treatments $\left(1.25\right.$ and $\left.2.5 \mathrm{mg} \mathrm{kg}^{-1}\right)$ did not differ as compared to the control group on days 1, 3, and 5. However, the OTM values in high-PHE concentration treatments ( 5 and $10 \mathrm{mg} \mathrm{kg}^{-1}$ ) were significantly higher than the control during the whole exposure period (Fig. 3D). This indicates significant DNA damage of coelomocytes in earthworms after exposure to PHE, especially at high dose levels.

The tail DNA\% is the percentage of DNA in the comet tail, which is used to quantify the degree of DNA damage in individual cells (Zhu et al. 2020). As illustrated in Fig. 3F, the results showed that the values of tail DNA\% in coelomocytes had the same variation trends with the OTM values after PHE exposure. All PHE-treated groups are minimal/low damage to the DNA of coelomocytes during the entire exposure period, except $10 \mathrm{mg} \mathrm{kg}^{-1}$ treatment for the 14th day, where PHE are middle damage to the coelomocyte 
DNA (Fig. 3F). Hence, PHE exposure can cause DNA damage of coelomocytes in earthworms, especially at high doses. Results from the comet assay are consistent with the changing trend of 8-OHdG level in the above research. Meanwhile, the value of OTM and Tail DNA\% of coelomocytes exhibited the same trend as that of the ROS level in adult E. fetida. The overall results indicate that PHE can induce DNA strand breaks through the formation of ROS and exhibit strong genotoxic potential to the coelomocytes in E. fetida.

\section{Effect of phenanthrene on avoidance behavior of adult $E$. fetida}

Avoidance tests can offer a rapid and low-mortality method for earthworm risk assessments of environmental contaminants (Garcia et al. 2008; Tang et al. 2016). The results of the avoidance behavior of adult E. fetida are exhibited in Fig. 4. No avoidance effects and earthworm escape were observed in the lowest PHE-treated groups (1.25 $\mathrm{mg} \mathrm{kg}^{-1}$ ) and control groups (Fig. 4). However, the observed avoidance effects (NR between 20 and $80 \%$ ) were found in the $2.5 \mathrm{mg} \mathrm{kg}^{-1}$ treatment groups. Earthworms displayed habitat function loss and avoidance behavior $(N R>80 \%)$ in the highest PHE-treated groups $\left(10 \mathrm{mg} \mathrm{kg}^{-1}\right)$ in higher treatment groups ( 5 and $10 \mathrm{mg} \mathrm{kg}^{-1}$ ) of PHE (Fig. 4). This result was accordant with the acute toxicity test that earthworms prefer to stay on or near the surface of soil substrate (Section 3.1). These results show that avoidance behavior is an essential endpoint in toxicological assessment and can provide extrapolations at the ecosystem level, even at low doses (Saggioro et al. 2019; Junior et al. 2020).

\section{Growth inhibition and reproductive toxicity of adult E. fetida after phenanthrene exposure}

Earthworm weight dynamics is an extremely sensitive marker of short- and long-term exposure to chemical toxicants (Sadeghi et al. 2018; Yao et al. 2021). In this study, the weight of adult E. fetida showed no significant changes between all PHE-treated groups on days 7 and 14 and the control group. However, exposure to higher PHE concentrations $\left(>1.25 \mathrm{mg} \mathrm{kg}^{-1}\right)$ significantly reduced the earthworm weight on days 21 and 28 compared to the control (Fig. 5A and C). Severe cases lead to the earthworm weight of E. fetida exposed to $10 \mathrm{mg} \mathrm{kg}^{-1}$ at $21 \mathrm{~d}$, and 10 and $1 \mathrm{mg} \mathrm{kg}^{-1}$ at the last exposure (28 d) was even lower than before the experiment (Fig. $5 \mathrm{~A}$ and $\mathrm{C}$ ).

Studies have reported that exposure to toxic chemicals can lead to the growth of earthworms was inhibited, with reduced weight being a common response to stress (Xiao et al. 2006; Liu et al. 2018; Qiao et al. 2019). The decreased weight is likely to be associated with the detoxification mechanism of earthworms involves the removal of external toxicants by energy metabolism (Yao et al. 2021). Moreover, a reduction in their energy reserves, such as protein, lipid, and glycogen in earthworms caused by toxic chemicals, might be another reason for this (Ye et al. 2016; Yao et al. 2020). Thus, we can conclude that PHE exposure disturbs the normal metabolism and physiological function of biomacromolecules in $E$. fetida, with detoxification leading to excessive metabolism, resulting in energy substance was excessively consumed, especially at high concentration levels have potential toxicity to E. fetida. 
Reproductive toxicity can influence the population development of any organism, and it is an essential indicator of ecological risk assessment after long-time exposure to toxicants or stresses (Zheng et al. 2008; Qiao et al. 2021). The effects of PHE on E. fetida reproduction in two soil is exhibited in Fig. 5B and $D$. The cocoon production and the number of juvenile of $E$. fetida significantly reduced with increasing the PHE concentrations on days 28 and 56 (Fig. 5 Band D). Previous studies found that exposure to environmental contaminants can damage the reproductive systems of earthworms, leading to abnormal sperm, loss of fertilization ability, and finally infertility (Liu et al. 2018; Qiao et al. 2019; Yao et al. 2020; He et al. 2021b). Consistent with these findings, we also believe that PHE can induce reproduction toxicity in E. fetida, especially in the case of exposure to high-dose treatments.

\section{Histopathological changes in adult E. fetida after exposure to phenanthrene}

Histopathology is a popular tool to assess the environmental impact of possible exogenous contaminants on various living organisms, including earthworms (Li et al. 2020a). The body wall of earthworms is mainly composed of the epithelium (epidermis), outer circular muscle, and inner longitudinal muscle layer (Zhang et al. 2015; Sun et al. 2022). In this study, the microstructure of the epidermis, circular muscle, and longitudinal muscle layer in the control treatment maintained their normal architecture after 28 days of PHE exposure (Fig. 6A1 and B1). However, in PHE-treated soils, the histological structure of $E$. fetida changed in varying degrees. A visible exfoliation of the cuticular layer was found in 1.25 and $10 \mathrm{mg} \mathrm{kg}^{-1}$ PHE treatment. Also, the circular muscle and longitudinal muscle layer were significantly damaged upon PHE exposure at day 28 (Fig. 6A2, A3, B2 and B3).

The inner layer of the E. fetida intestine is intestinal epithelial tissue, and the outer layer of the earthworm intestine is chlorogenic tissue, which separates the intestine from the body wall (Li et al. 2020b). No obvious damage to the intestinal epithelial and chlorogenic tissues was found in the $1.25 \mathrm{mg} \mathrm{kg}^{-1}$ exposure group compared to the control (Fig. 6A1 and A2). However, the chlorogenic and the intestinal epithelial tissues of E. fetida were severely damaged in the $10 \mathrm{mg} \mathrm{kg}^{-1}$ PHE-treated group (Fig. 6A3). Also, PHE exposure caused obvious degradation of intestinal tract, and this was particularly true with high concentrations $\left(10 \mathrm{mg} \mathrm{kg}^{-1}\right)$ (Fig. A3). Usually, the intestines and epidermis of earthworms are the main tissues exposed to pollutants in the soil environment through direct contact, digestion, and absorption. Thus, significant lesions may occur after these tissues are heavily damaged, eventually leading to death (Li et al. 2020a). Our results suggest that high-dose PHE exposure can injure the intestinal tract and epidermal tissues of E. fetida.

Figure $6 \mathrm{C}$ shows the histopathological observations of the seminal vesicle in E. fetida after 28 days of exposure. As illustrated in Figure $6 \mathrm{C} 1$, the seminal vesicles of E. fetida had a clear outline and complete structure in the control group. In the $1.25 \mathrm{mg} \mathrm{kg}^{-1} \mathrm{PHE}$-treated group, the seminal vesicles began to shrink, showing a slight degree of damage to its structure (Figure 6C2). When earthworms were exposed to $10 \mathrm{mg} \mathrm{kg}^{-1} \mathrm{PHE}$, the seminal vesicles became dissipate and shrink to an indistinguishable level (Figure $6 \mathrm{C3}$ ). Our results are similar with Sun et al. (2021), who found that pyrene exposure could cause heavy damage to seminal vesicles of E. fetida. Similar histopathological changes were also found when 
earthworms were exposed to petroleum hydrocarbons (Li et al. 2020b). Liang et al. (2017) reported that the health of seminal vesicle tissue was related to the reproduction rate of earthworms. It may be the reason for E. fetida with poor reproductive performance (decreased cocoons and juveniles) after exposure to PHE.

\section{Integrated assessment of biochemical response in adult $\mathrm{E}$. fetida after exposure to phenanthrene}

In order to compare the toxicity of PHE on adult E. fetida at different doses and exposure times, a comprehensive biomarker response index (IBRv2) was employed (Sanchez et al. 2013). This method has the advantage of visualization and can clarify the relationship between various biological indicators after exposure to pollutants and distinguish the pollution degree of multiple biomarkers in earthworms ( $\mathrm{Li}$ et al. 2020a; Zhang et al. 2021). IBRv2 is the sum of the standardized values of all indicators, with higher values represent greater toxicity. The greater standardized value means the greater impact of PHE on earthworms (Normalized value greater than 0 indicates activated, less than 0 indicates suppressed) (Sanchez et al. 2013; Zhu et al. 2020).

The standardized values of all biochemical response biomarkers in E. fetida earthworms exposed to PHE at different doses and exposure times are exhibited in Fig. 7. These values can provide a visual illustration of the toxic effects of PHE on E. fetida earthworms. Compared to other biomarkers, the change of OTM values was higher in all treatment groups, except in the groups treated with $1.25 \mathrm{mg} \mathrm{kg}^{-1}$ PHE at 1 and $5 \mathrm{~d}$ (Fig. 7), thus indicating that DNA in E. fetida would be the most negatively affected in the presence of PHE. Also, the activities of the detoxification enzymes (GST and CarE) were in a repressive state for the majority of the time, especially a longer exposure (7 and $14 \mathrm{~d}$ ), indicating GST and CarE are involved in detoxification and metabolism processes of PHE. Additionally, SOD, MDA, TAC, and $80 \mathrm{HdG}$ were also susceptible to damage in earthworms. Hence, these biomarkers can be used as indicators to reflect the toxic effects of toxic substances including PHE.

In general, the values of IBRv2 are proportional to the comprehensive toxicity of exogenous contaminants to earthworms (Zhu et al. 2020). The changes in the sum of IBRv2 index value in all PHE-treated groups at different exposure times are shown in Fig. 7. As depicted in Fig. 7, PHE at higher concentration (5 and $10 \mathrm{mg} \mathrm{kg}^{-1}$ ) exhibited a greater impact on all biomarkers than that in lower treatment groups (1.25 and $2.5 \mathrm{mg} \mathrm{kg}^{-1}$ ) at different exposure times (1, 3, 5, 7, and $14 \mathrm{~d}$ ). Also, long-term exposures (7 and $14 \mathrm{~d}$ ) exhibited a larger impact on multiple biomarkers in E. fetida compared to short-term exposure ( 1 and $3 \mathrm{~d})$, showing a clear time- and dose-effect after exposure to PHE. These results indicated that PHE exposure cause more serious negative effects on $E$. fetida, especially in the high-dose and long-term exposure groups. A more important finding was that the comprehensive toxicity of PHE to $E$. fetida earthworms showed a tendency to decrease after $14 \mathrm{~d}$ of exposure. The result suggested that the influence of PHE on E. fetida gradually reduced with increasing exposure time. It may be likely due to earthworms adapting to the soil ontaminated with this pollutant. Further research is needed to clarify the soil parameters and types that influence the toxicity of PHE to earthworms. 


\section{Conclusions}

The results of this study emphasize the comprehensive effects of natural soil matrix on the toxicological response of Eisenia fetida to phenanthrene. Our results verified that PHE had severe acute toxicity to adult $E$. fetida in natural soil. PHE exposure resulted in the loss of habitat function in 5 and $10 \mathrm{mg} \mathrm{kg}^{-1}$ PHE-treated groups. Abnormal mitochondria induced by PHE resulted in excessive ROS production and the elevated ROS levels increased oxidative damage to biomacromolecules (lipid peroxidation, protein carbonylation, and DNA damage) in E. fetida. To scavenge excess ROS and free radicals, the antioxidases and small-molecule antioxidants (SOD, CAT, POD, GST, CarE, and TAC) in earthworms were all involved in oxidative stress response. Besides, PHE exposure can seriously damage the tissues of adult $E$. fetida, including the intestine, body wall, and seminal vesicle. These toxic effects led to growth inhibition and decreased cocoons and juveniles produced by $E$. fetida. Furthermore, the integrated toxicity effects of PHE on the multiple biomarkers of $E$. fetida at different doses and exposure times were evaluated by using the IBR index, and the results showed that PHE was more toxic to E. fetida earthworms in the high-dose and long-term exposure conditions. The Olive tail moment of $E$. fetida coelomocytes DNA can be applied as a sensitive parameter for assessing oxidative stress induced by PHE. In summary, PHE-induced ROS production and excessive ROS leads to detrimental oxidative stress occur, breaking the antioxidant defense system in earthworms and triggering oxidative damage, and causing behavior changes and normal histopathological structure was damaged, which ultimately resulting in growth inhibition, genotoxicity, and reproductive toxicity.

\section{Declarations}

Acknowledgments We thank LetPub (www.letpub.com) for linguistic assistance during manuscript preparation.

Author contribution Falin He: Conceptualized the study, performed formal analyses, investigation, methodology, data curation, drafted the original manuscript. Hanmei Yu: Investigation, Reviewed and edited the manuscript. Huijian Shi: Investigation and Methodology. Xiangxiang Li: Investigation. Shanshan Chu: Investigation. Chengqian Huo: Investigation. Rutao Liu: Conceptualized the study, Validation, Reviewed \& edited the manuscript, Project administration, and Funding acquisition.

Funding This work was supported by NSFC (U1806216, 21777088, and 21477067), the Cultivation Fund of the Key Scientific and Technical Innovation Project, Research Fund for the Doctoral Program of Higher Education and Ministry of Education of China $(708058,20130131110016)$, and the Science and Technology Development Plan of Shandong Province (2014GSF117027).

Data availability The datasets used or analyzed during the current study are available from the corresponding author on reasonable request.

Ethics approval and consent to participate Not applicable. 
Consent for publication Not applicable

Competing interests None

\section{References}

1. Achten C, Andersson JT (2015) Overview of Polycyclic Aromatic Compounds (PAC). Polycyclic aromatic compounds 35: 177-186

2. Agnihotri N, Mishra PC (2009) Mutagenic Product Formation Due to Reaction of Guanine Radical Cation with Nitrogen Dioxide. J Phys Chem B 113: 3129-3138

3. Andreoni V, Cavalca L, Rao MA, Nocerino G, Bernasconi S, Dell'Amico E, Colombo M, Gianfreda L (2004) Bacterial communities and enzyme activities of PAHs polluted soils. Chemosphere 57: 401412

4. Asakawa T, Matsushita S (1980) Coloring conditions of thiobarbituric acid test for detecting lipid hydroperoxides. Lipids 15: 137-140

5. Askari MS, Alamdari P, Chahardoli S, Afshari A (2020) Quantification of heavy metal pollution for environmental assessment of soil condition. Environ Monit Assess 192

6. Bradford MM (1976) A rapid and sensitive method for the quantitation of microgram quantities of protein utilizing the principle of protein-dye binding. Anal Biochem 72: 248-254

7. Charan M, Das S, Mishra S, Chatterjee N, Varikuti S, Kaul K, Misri S, Ahirwar DK, Satoskar AR, Ganju RK (2020) Macrophage migration inhibitory factor inhibition as a novel therapeutic approach against triple-negative breast cancer. Cell Death Dis 11: 774

8. Chen J, Chen W, Zhang L, Li K, Peng S, He M, Hu L (2015) Safety of ultrasound-guided ultrasound ablation for uterine fibroids and adenomyosis: A review of 9988 cases. Ultrason Sonochem 27: 671676

9. Chen M, Huang P, Chen L (2013) Polycyclic aromatic hydrocarbons in soils from Urumqi, China: distribution, source contributions, and potential health risks. Environ Monit Assess 185: 5639-5651

10. Chi F-H (2014) The Influence of Black Carbon on the Sorption and Desorption of Two Model PAHs in Natural Soils. B Environ Contam Tox 92: 44-49

11. Chikere CB, Chikere BO, Okpokwasili GC (2012) Bioreactor-based bioremediation of hydrocarbonpolluted Niger Delta marine sediment, Nigeria. 3 Biotech 2: 53-66

12. Choudhury S, Panda SK (2005) Toxic Effects, Oxidative Stress and Ultrastructural Changes in Moss Taxithelium Nepalense (Schwaegr.) Broth. Under Chromium and Lead Phytotoxicity. Water Air Soil Poll 167: 73-90

13. Collange B, Wheelock CE, Rault M, Mazzia C, Capowiez Y, Sanchez-Hernandez JC (2010) Inhibition, recovery and oxime-induced reactivation of muscle esterases following chlorpyrifos exposure in the earthworm Lumbricus terrestris. Environ Pollut 158: 2266-2272 
14. Delmastro-Greenwood MM, Tse HM, Piganelli JD (2014) Effects of metalloporphyrins on reducing inflammation and autoimmunity. Antioxid Redox Signal 20: 2465-77

15. Deng S, Zeng D (2017) Removal of phenanthrene in contaminated soil by combination of alfalfa, white-rot fungus, and earthworms. Environ Sci Pollut R 24: 7565-7571

16. Dimashki M, Lim LH, Harrison RM, Harrad S (2001) Temporal trends, temperature dependence, and relative reactivity of atmospheric polycyclic aromatic hydrocarbons. Environ Sci Technol 35: 2264-7

17. Duan X, Xu M, Zhou Y, Yan Z, Du Y, Zhang L, Zhang C, Bai L, Nie J, Chen G, Li F (2016) Effects of soil properties on copper toxicity to earthworm Eisenia fetida in 15 Chinese soils. Chemosphere 145: 185192

18. Ece A, Kelekçi S, Kocamaz H, Hekimoğlu A, Balık H, Yolbaş İ, Erel Ö (2008) Antioxidant enzyme activities, lipid peroxidation, and total antioxidant status in children with Henoch-Schönlein purpura. Clin Rheumatol 27: 163-169

19. Ečimović S, Grgić M, Bošnjaković R, Velki M (2019) Biomarker responses in earthworm coelomocyte extract - Noninvasively collected sample for pesticide effect assessment. Chemosphere 234: 837844

20. El-Mas MM, Mohy El-Din MM, Helmy MM, Omar AG (2012) Redox imbalances incite the hypertensive, baroreflex, and autonomic effects of cyclosporine in rats. Eur J Pharmacol 694: 82-88

21. Elyamine AM, Hu C (2020) Earthworms and rice straw enhanced soil bacterial diversity and promoted the degradation of phenanthrene. Environ Sci Eur 32: 124

22. England K, Driscoll CO, Cotter TG (2006) ROS and protein oxidation in early stages of cytotoxic drug induced apoptosis. Free Radical Res 40: 1124-1137

23. Eom IC, Rast C, Veber AM, Vasseur P (2007) Ecotoxicity of a polycyclic aromatic hydrocarbon (PAH)contaminated soil. Ecotox Environ Safe 67: 190-205

24. Fida TT, Breugelmans P, Lavigne R, Coronado E, Johnson DR, Van Der Meer JR, Mayer AP, Heipieper HJ, Hofkens J, Springael D (2012) Exposure to Solute Stress Affects Genome-Wide Expression but Not the Polycyclic Aromatic Hydrocarbon-Degrading Activity of Sphingomonas sp. Strain LH128 in Biofilms. Appl Environ Microbiol 78: 8311-8320

25. Gajski G, Žegura B, Ladeira C, Pourrut B, Del Bo' C, Novak M, Sramkova M, Milić M, Gutzkow KB, Costa S, Dusinska M, Brunborg G, Collins A (2019) The comet assay in animal models: From bugs to whales - (Part 1 Invertebrates). Mutation Research/Reviews in Mutation Research 779: 82-113

26. Gan S, Lau EV, Ng HK (2009) Remediation of soils contaminated with polycyclic aromatic hydrocarbons (PAHs). J Hazard Mater 172: 532-549

27. Garcia M, Römbke J, de Brito MT, Scheffczyk A (2008) Effects of three pesticides on the avoidance behavior of earthworms in laboratory tests performed under temperate and tropical conditions. Environ Pollut 153: 450-456

28. He F, Liu Q, Jing M, Wan J, Huo C, Zong W, Tang J, Liu R (2021a) Toxic mechanism on phenanthreneinduced cytotoxicity, oxidative stress and activity changes of superoxide dismutase and catalase in earthworm (Eisenia foetida): A combined molecular and cellular study. J Hazard Mater 418: 126302 
29. He F, Wan J, Li X, Chu S, Sun N, Liu R (2021b) Toxic effects of benzovindiflupyr, a new SDHI-type fungicide on earthworms (Eisenia fetida). Environ Sci Pollut $\mathrm{R}$

30. Hong XS, Qin JH, Chen R, Yuan LL, Zha JM, Huang C, Li N, Ji XY, Wang ZJ (2017) PhenanthreneInduced Apoptosis and Its Underlying Mechanism. Environ Sci Technol 51: 14397-14405

31. Hu Y, Yu L, Xia F, Liang F, Cheng C, Huang Y, Xiao L (2019) Effect of laparoscopic myomectomy on serum levels of IL-6 and TAC, and ovarian function. Exp Ther Med 18

32. ISO (2008) ISO 17512-1: Soil Quality - Avoidance Test for Determining the Quality of Soils and Effects of Chemicals on Behavior Part 1: Test with Earthworms (Eisenia fetida and Eisenia andrei). ISO, Genève, Switzerland

33. Jia H, Zhao S, Nulaji G, Tao K, Wang F, Sharma VK, Wang C (2017) Environmentally Persistent Free Radicals in Soils of Past Coking Sites: Distribution and Stabilization. Environ Sci Technol 51: 60006008

34. Jiang Q, Yin J, Chen J, Ma X, Wu M, Liu G, Yao K, Tan B, Yin Y (2020) Mitochondria-Targeted Antioxidants: A Step towards Disease Treatment. Oxidative medicine and cellular longevity 2020: 8837893-8837893

35. Johnsen AR, Wick LY, Harms H (2005) Principles of microbial PAH-degradation in soil. Environ Pollut 133: $71-84$

36. Junior SFS, Vallerie Q, de Farias Araujo G, Soares LOS, Oliveira da Silva E, Correia FV, Saggioro EM (2020) Triclocarban affects earthworms during long-term exposure: Behavior, cytotoxicity, oxidative stress and genotoxicity assessments. Environ Pollut 267: 115570

37. Końca K, Lankoff A, Banasik A, Lisowska H, Kuszewski T, Góźdź S, Koza Z, Wojcik A (2003) A crossplatform public domain PC image-analysis program for the comet assay. Mutat Res-Gen Tox En 534: $15-20$

38. Lawler JM, Song W, Demaree SR (2003) Hindlimb unloading increases oxidative stress and disrupts antioxidant capacity in skeletal muscle. Free Radical Bio Med 35: 9-16

39. Li M, Ma X, Saleem M, Wang X, Sun L, Yang Y, Zhang Q (2020a) Biochemical response, histopathological change and DNA damage in earthworm (Eisenia fetida) exposed to sulfentrazone herbicide. Ecol Indic 115: 106465

40. Li Y, Wang X, Sun Z (2020b) Ecotoxicological effects of petroleum-contaminated soil on the earthworm Eisenia fetida. J Hazard Mater 393: 122384

41. Liang J, Xia X, Zhang W, Zaman WQ, Lin K, Hu S, Lin Z (2017) The biochemical and toxicological responses of earthworm (Eisenia fetida) following exposure to nanoscale zerovalent iron in a soil system. Environ Sci Pollut Res Int 24: 2507-2514

42. Liu T, Wang $X$, You X, Chen D, Li Y, Wang F (2017) Oxidative stress and gene expression of earthworm (Eisenia fetida) to clothianidin. Ecotox Environ Safe 142: 489-496

43. Liu T, Wang X, Chen D, Li Y, Wang F (2018) Growth, reproduction and biochemical toxicity of chlorantraniliprole in soil on earthworms (Eisenia fetida). Ecotox Environ Safe 150: 18-25 
44. Luo S, Wehr NB (2009) Protein carbonylation: avoiding pitfalls in the 2,4-dinitrophenylhydrazine assay. Redox Rep 14: 159-66

45. Ma W-L, Liu L-Y, Tian C-G, Qi H, Jia H-L, Song W-W, Li Y-F (2015) Polycyclic aromatic hydrocarbons in Chinese surface soil: occurrence and distribution. Environ Sci Pollut R 22: 4190-4200

46. Maletić SP, Beljin JM, Rončević SD, Grgić MG, Dalmacija BD (2019) State of the art and future challenges for polycyclic aromatic hydrocarbons is sediments: sources, fate, bioavailability and remediation techniques. J Hazard Mater 365: 467-482

47. Meng M, Guo M, Feng C, Wang R, Cheng D, Wang C (2019) Water-soluble polysaccharides from Grifola Frondosa fruiting bodies protect against immunosuppression in cyclophosphamide-induced mice via JAK2/STAT3/SOCS signal transduction pathways. Food Funct 10: 4998-5007

48. Mittler R (2002) Oxidative stress, antioxidants and stress tolerance. Trends Plant Sci 7: 405-410

49. Nam TH, Jeon HJ, Mo HH, Cho K, Ok YS, Lee SE (2015) Determination of biomarkers for polycyclic aromatic hydrocarbons (PAHs) toxicity to earthworm (Eisenia fetida). Environ Geochem Health 37: 943-51

50. Nam TH, Kim L, Jeon HJ, Kim K, Ok YS, Choi SD, Lee SE (2017) Biomarkers indicate mixture toxicities of fluorene and phenanthrene with endosulfan toward earthworm (Eisenia fetida). Environ Geochem Health 39: 307-317

51. OECD (1984) Test No. 207: Earthworm Acute ToxicityTests. OECD Guidelines for the Testing of Chemicals: Paris

52. Olive PL, Banath JP, Durand RE (2012) Heterogeneity in Radiation-Induced DNA Damage and Repair in Tumor and Normal Cells Measured Using the "Comet" Assay. Radiat Res 178: AV35-AV42

53. Osuji LC, Idung ID, Ojinnaka CM (2006) Preliminary Investigation on Mgbede-20 Oil-Polluted Site in Niger Delta, Nigeria. Chem Biodivers 3: 568-577

54. Picariello E, Baldantoni D, De Nicola F (2020) Acute effects of PAH contamination on microbial community of different forest soils. Environ Pollut 262: 114378

55. Pickett CB, Lu AY (1989) Glutathione S-transferases: gene structure, regulation, and biological function. Annu Rev Biochem 58: 743-64

56. Ping LF, Luo YM, Zhang HB, Li QB, Wu LH (2007) Distribution of polycyclic aromatic hydrocarbons in thirty typical soil profiles in the Yangtze River Delta region, east China. Environ Pollut 147: 358-365

57. Qiao Z, Zhang F, Yao X, Yu H, Sun S, Li X, Zhang J, Jiang X (2019) Growth, DNA damage and biochemical toxicity of cyantraniliprole in earthworms (Eisenia fetida). Chemosphere 236: 124328

58. Qiao Z, Yao X, Liu X, Zhang J, Du Q, Zhang F, Li X, Jiang X (2021) Transcriptomics and enzymology combined five gene expressions to reveal the responses of earthworms (Eisenia fetida) to the longterm exposure of cyantraniliprole in soil. Ecotox Environ Safe 209: 111824

59. Rubio-Clemente A, Torres-Palma RA, Peñuela GA (2014) Removal of polycyclic aromatic hydrocarbons in aqueous environment by chemical treatments: A review. Sci Total Environ 478: 201225 
60. Sadeghi L, Tanwir F, Yousefi Babadi V (2018) Physiological and Biochemical Effects of Echium Amoenum Extract on $\mathrm{Mn}^{2+}$-Imposed Parkinson Like Disorder in Rats. Adv Pharm Bull 8: 705-713

61. Saggioro EM, do Espírito Santo DG, Sales Júnior SF, Hauser-Davis RA, Correia FV (2019) Lethal and sublethal effects of acetamiprid on Eisenia andrei: Behavior, reproduction, cytotoxicity and oxidative stress. Ecotox Environ Safe 183: 109572

62. Saint-Denis M, Labrot F, Narbonne JF, Ribera D (1998) Glutathione, Glutathione-Related Enzymes, and Catalase Activities in the Earthworm Eisenia fetida andrei. Arch Environ Con Tox 35: 602-614

63. Sanchez W, Burgeot T, Porcher JM (2013) A novel "Integrated Biomarker Response" calculation based on reference deviation concept. Environ Sci Pollut Res Int 20: 2721-2725

64. Shin G-C, Kim C, Lee J-M, Cho W-S, Lee S-G, Jeong M, Cho J, Lee K (2009) Apigenin-induced apoptosis is mediated by reactive oxygen species and activation of ERK1/2 in rheumatoid fibroblastlike synoviocytes. Chem-Biol Interact 182: 29-36

65. Sies H (1997) Oxidative stress: oxidants and antioxidants. Exp Physiol 82: 291-5

66. Song P, Gao J, Li X, Zhang C, Zhu L, Wang J, Wang J (2019) Phthalate induced oxidative stress and DNA damage in earthworms (Eisenia fetida). Environ Int 129: 10-17

67. Song Y, Zhu LS, Wang J, Wang JH, Liu W, Xie H (2009) DNA damage and effects on antioxidative enzymes in earthworm (Eisenia foetida) induced by atrazine. Soil Biol Biochem 41: 905-909

68. Sun K, Li M, Song Y, Tang J, Liu R (2022) Organism and molecular-level responses of superoxide dismutase interaction with 2-pentanone. Chemosphere 286: 131707

69. Sun N, Liu Q, Wang J, He F, Jing M, Chu S, Zong W, Liu R, Gao C (2021) Probing the biological toxicity of pyrene to the earthworm Eisenia fetida and the toxicity pathways of oxidative damage: A systematic study at the animal and molecular levels. Environ Pollut 289: 117936

70. Tang H, Yan Q, Wang X, Ai X, Robin P, Matthew C, Qiu J, Li X, Li Y (2016) Earthworm (Eisenia fetida) behavioral and respiration responses to sublethal mercury concentrations in an artificial soil substrate. Appl Soil Ecol 104: 48-53

71. Tomasetig F, Tebby C, Graillot V, Zeman F, Pery A, Cravedi JP, Audebert M (2020) Comparative genotoxic potential of 27 polycyclic aromatic hydrocarbons in three human cell lines. Toxicol Lett 326: 99-105

72. Turillazzi E, Cerretani D, Cantatore S, Fiaschi Al, Frati P, Micheli L, Neri M, Cipolloni L, Di Paolo M, Pinchi E, Riezzo I, Santurro A, Vullo A, Fineschi V (2017) Myocardial oxidative damage is induced by cardiac Fas-dependent and mitochondria-dependent apoptotic pathways in human cocaine-related overdose. Sci Rep 7

73. Wang D, Zhu S, Wang L, Zhen Q, Han F, Zhang X (2020) Distribution, Origins and Hazardous Effects of Polycyclic Aromatic Hydrocarbons in Topsoil Surrounding Oil Fields: A Case Study on the Loess Plateau, China. Int J Env Res Pub He 17: 1390

74. Wang S-J, Yan Z-G, Guo G-L, Lu G-L, Wang Q-H, Li F-S (2010) Ecotoxicity assessment of aged petroleum sludge using a suite of effects-based end points in earthworm Eisenia fetida. Environ 
Monit Assess 169: 417-428

75. Wang X, Zhu X, Peng Q, Wang Y, Ge J, Yang G, Wang X, Cai L, Shen W (2019) Multi-level ecotoxicological effects of imidacloprid on earthworm (Eisenia fetida). Chemosphere 219: 923-932

76. Weng S-L, Huang K-Y, Kaunang FJ, Huang C-H, Kao H-J, Chang T-H, Wang H-Y, Lu J-J, Lee T-Y (2017) Investigation and identification of protein carbonylation sites based on position-specific amino acid composition and physicochemical features. BMC Bioinformatics 18: 66

77. Wilcke W (2007) Global patterns of polycyclic aromatic hydrocarbons (PAHs) in soil. Geoderma 141: 157-166

78. Wu S, Zhang H, Zhao S, Wang J, Li H, Chen J (2012a) Biomarker responses of earthworms (Eisenia fetida) exposured to phenanthrene and pyrene both singly and combined in microcosms. Chemosphere 87: 285-293

79. Wu SJ, Wu EM, Qiu LQ, Zhong WH, Chen JM (2011) Effects of phenanthrene on the mortality, growth, and anti-oxidant system of earthworms (Eisenia fetida) under laboratory conditions. Chemosphere 83: 429-434

80. Wu SJ, Zhang HX, Zhao SL, Wang JL, Li HL, Chen JM (2012b) Biomarker responses of earthworms (Eisenia fetida) exposured to phenanthrene and pyrene both singly and combined in microcosms. Chemosphere 87: 285-293

81. Xiao N, Jing B, Ge F, Liu X (2006) The fate of herbicide acetochlor and its toxicity to Eisenia fetida under laboratory conditions. Chemosphere 62: 1366-1373

82. Xu Y, Li B, Hou K, Du Z, Allen SC, Zhu L, Li W, Zhu L, Wang J, Wang J (2021) Ecotoxicity evaluation of azoxystrobin on Eisenia fetida in different soils. Environ Res 194: 110705

83. Yao X, Zhang F, Qiao Z, Yu H, Sun S, Li X, Zhang J, Jiang X (2020) Toxicity of thifluzamide in earthworm (Eisenia fetida). Ecotox Environ Safe 188: 109880

84. Yao X, Qiao Z, Zhang F, Liu X, Du Q, Zhang J, Li X, Jiang X (2021) Effects of a novel fungicide benzovindiflupyr in Eisenia fetida: Evaluation through different levels of biological organization. Environ Pollut 271: 116336

85. Ye X, Xiong K, Liu J (2016) Comparative toxicity and bioaccumulation of fenvalerate and esfenvalerate to earthworm Eisenia fetida. J Hazard Mater 310: 82-88

86. Zhang J, Zhang C, Du Z, Zhu L, Wang J, Wang J, Li B (2020) Emerging contaminant 1,3,6,8tetrabromocarbazole induces oxidative damage and apoptosis during the embryonic development of zebrafish (Danio rerio). Sci Total Environ 743: 140753

87. Zhang Q, Zhang B, Wang C (2014) Ecotoxicological effects on the earthworm Eisenia fetida following exposure to soil contaminated with imidacloprid. Environ Sci Pollut R 21: 12345-12353

88. Zhang W, Liu K, Li J, Liang J, Lin K (2015) Impacts of BDE209 addition on Pb uptake, subcellular partitioning and gene toxicity in earthworm (Eisenia fetida). J Hazard Mater 300: 737-744

89. Zhang W, Xia X, Wang J, Zhu L, Wang J, Wang G, Chen Y, Kim YM (2021) Oxidative stress and genotoxicity of nitenpyram to earthworms (Eisenia foetida). Chemosphere 264: 128493 
90. Zheng S, Song Y, Qiu X, Sun T, Leigh Ackland M, Zhang W (2008) Annetocin and TCTP expressions in the earthworm Eisenia fetida exposed to PAHs in artificial soil. Ecotox Environ Safe 71: 566-573

91. Zhu L, Li B, Wu R, Li W, Wang J, Wang J, Du Z, Juhasz A, Zhu L (2020) Acute toxicity, oxidative stress and DNA damage of chlorpyrifos to earthworms (Eisenia fetida): The difference between artificial and natural soils. Chemosphere 255: 126982

\section{Figures}

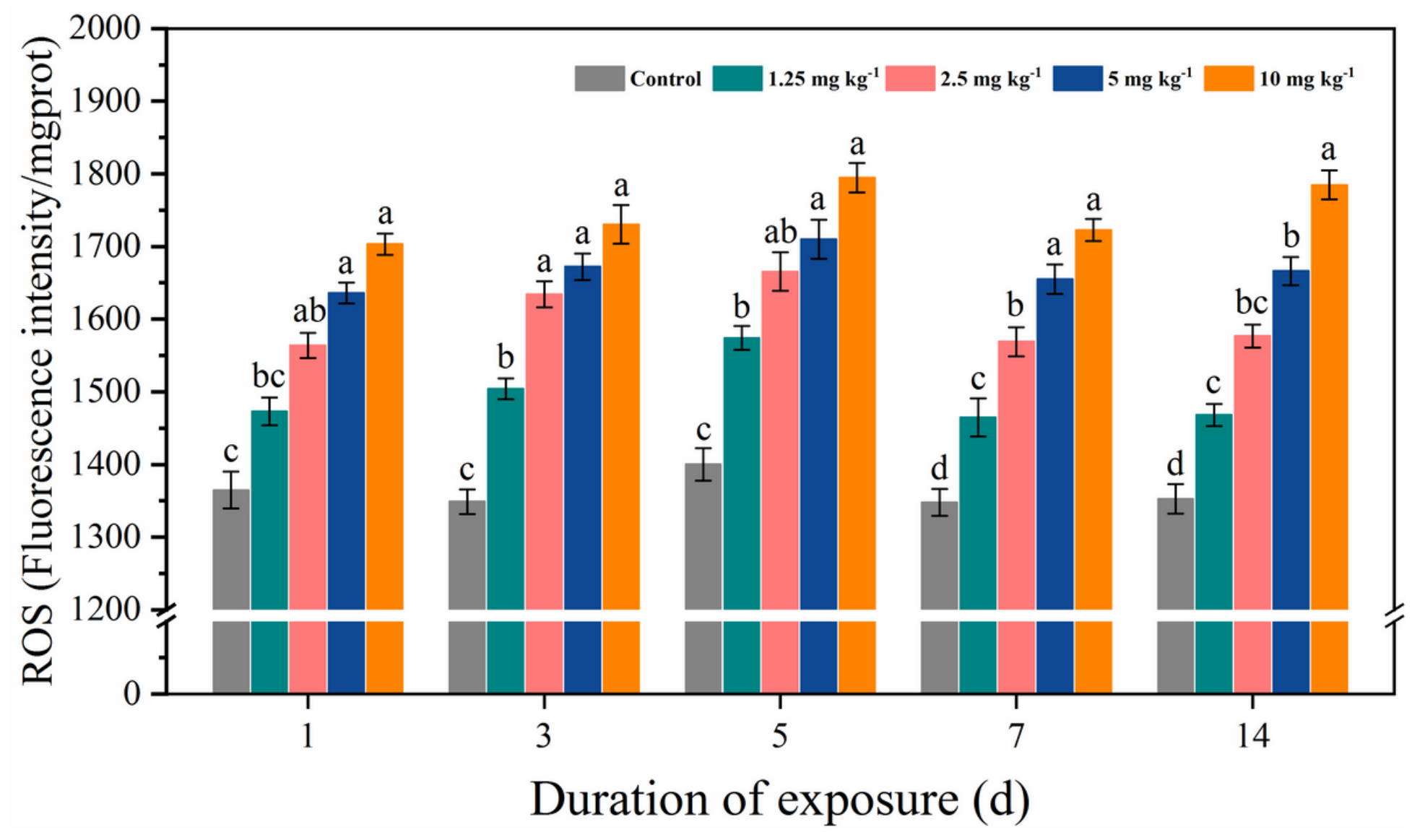

Figure 1

Effects of phenanthrene on the ROS levels in Eisenia fetida on days 1, 3, 5, 7, and 14. Different letters indicate significant differences at $P<0.05$ level among treatment groups. 

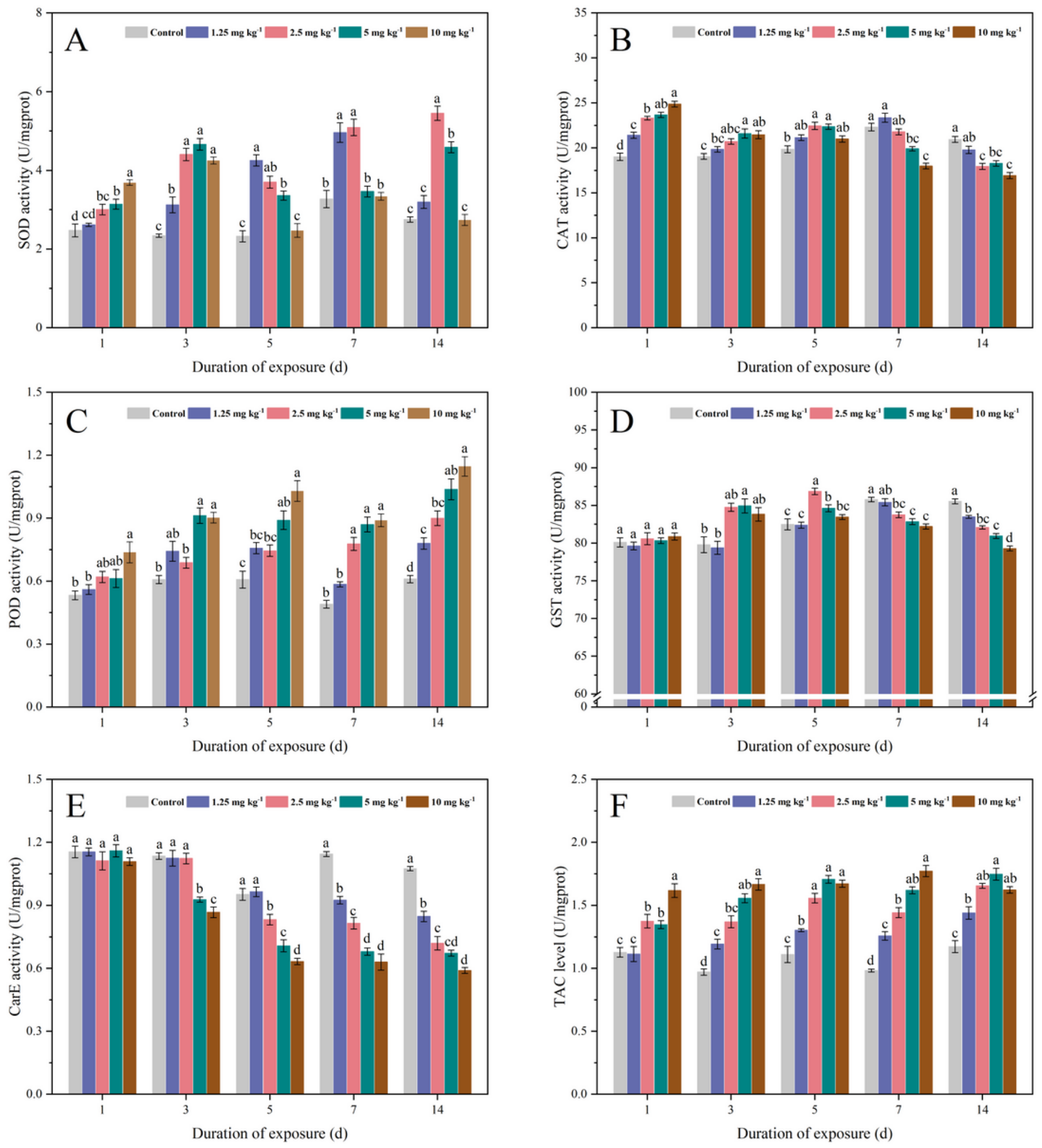

Figure 2

Effects of phenanthrene on the activity changes of antioxidant response and detoxification enzymes (A: SOD; B: CAT; C: POD; D: GST; E: CarE; F:TAC) in Eisenia fetida exposed for 1, 3, 5, 7, and 14 days. Different letters indicate significant differences at $\mathrm{P}<0.05$ level among groups. 

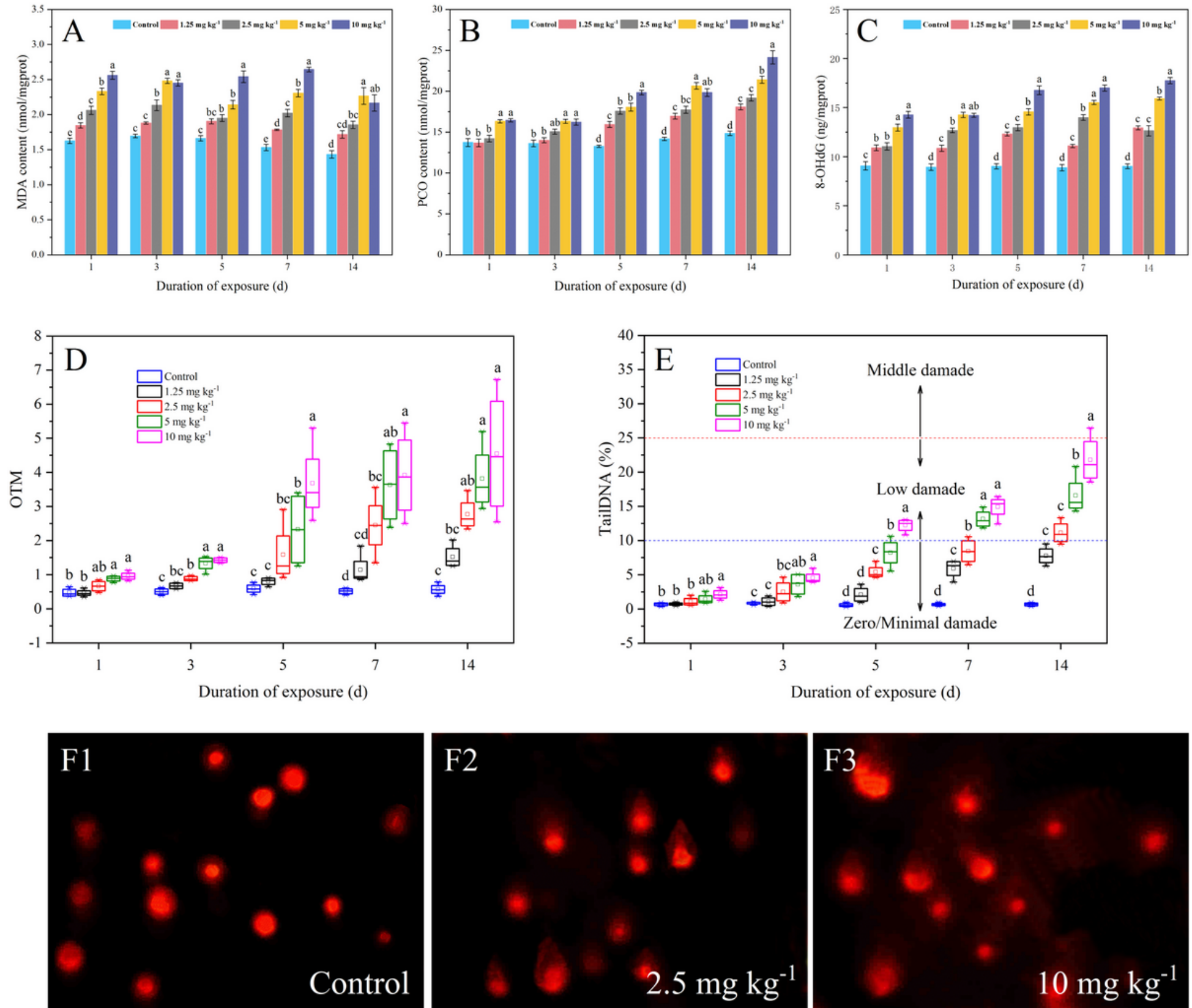

\section{Figure 3}

Effects of phenanthrene on the oxidative damage degree (A: MDA; B: PCO; C: 8-OHdG; D: OTM; E: TailDNA\%) in Eisenia fetida exposed for 1, 3, 5, 7, and 14 days. Representative pictures of DNA damage (F1: Control; F2: $2.5 \mathrm{mg} \mathrm{kg-1;} \mathrm{F3:} 10 \mathrm{mg} \mathrm{kg-1}$ ) of coelomocytes in E. fetida after $14 \mathrm{~d}$ exposure of phenanthrene. Different letters indicate significant differences $(P<0.05)$ among groups. 


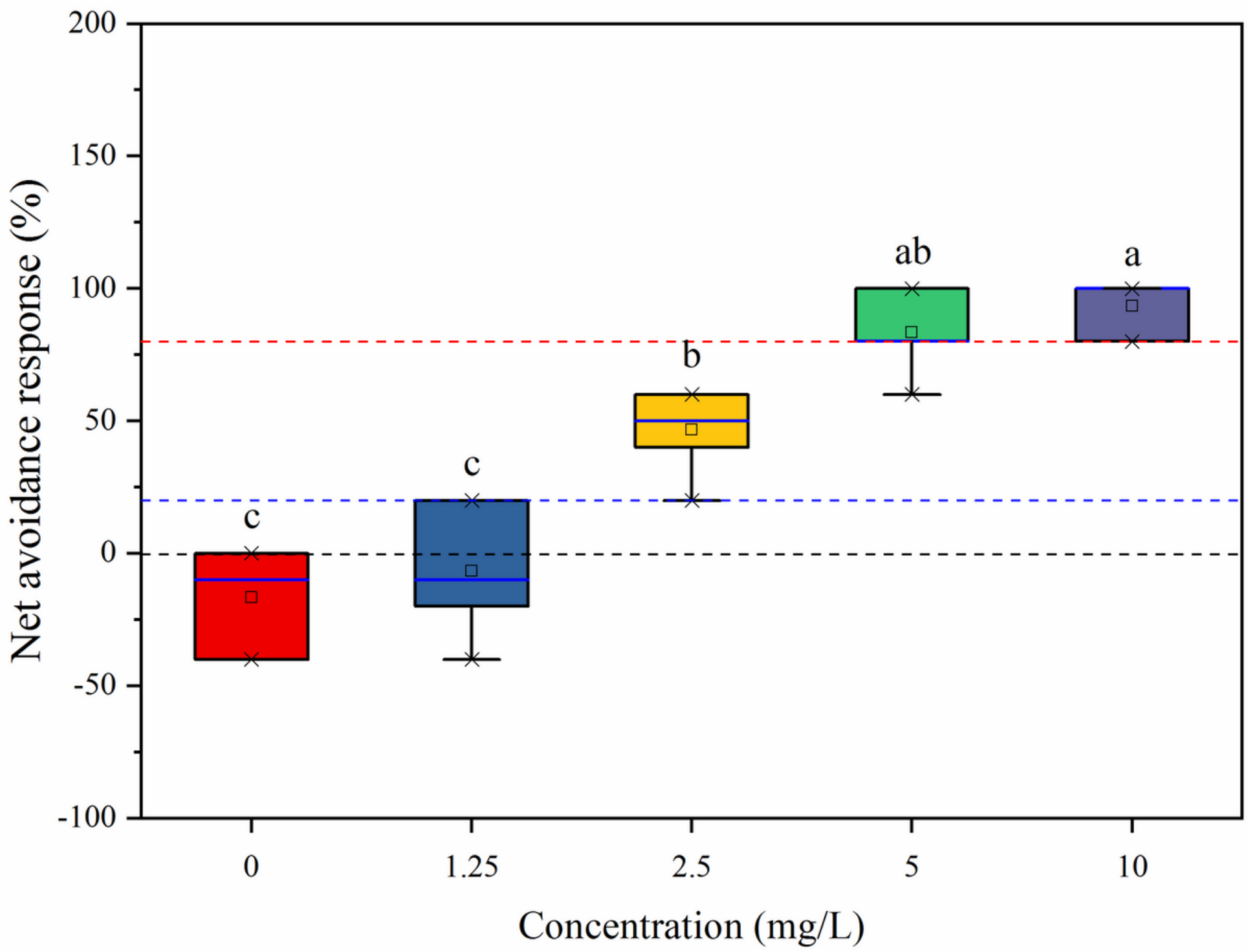

Figure 4

Avoidance behavior of Eisenia fetida in the natural soil contaminated with phenanthrene for $48 \mathrm{~h}$. Different letters indicate significant differences $(P<0.05)$ among treatment groups. 

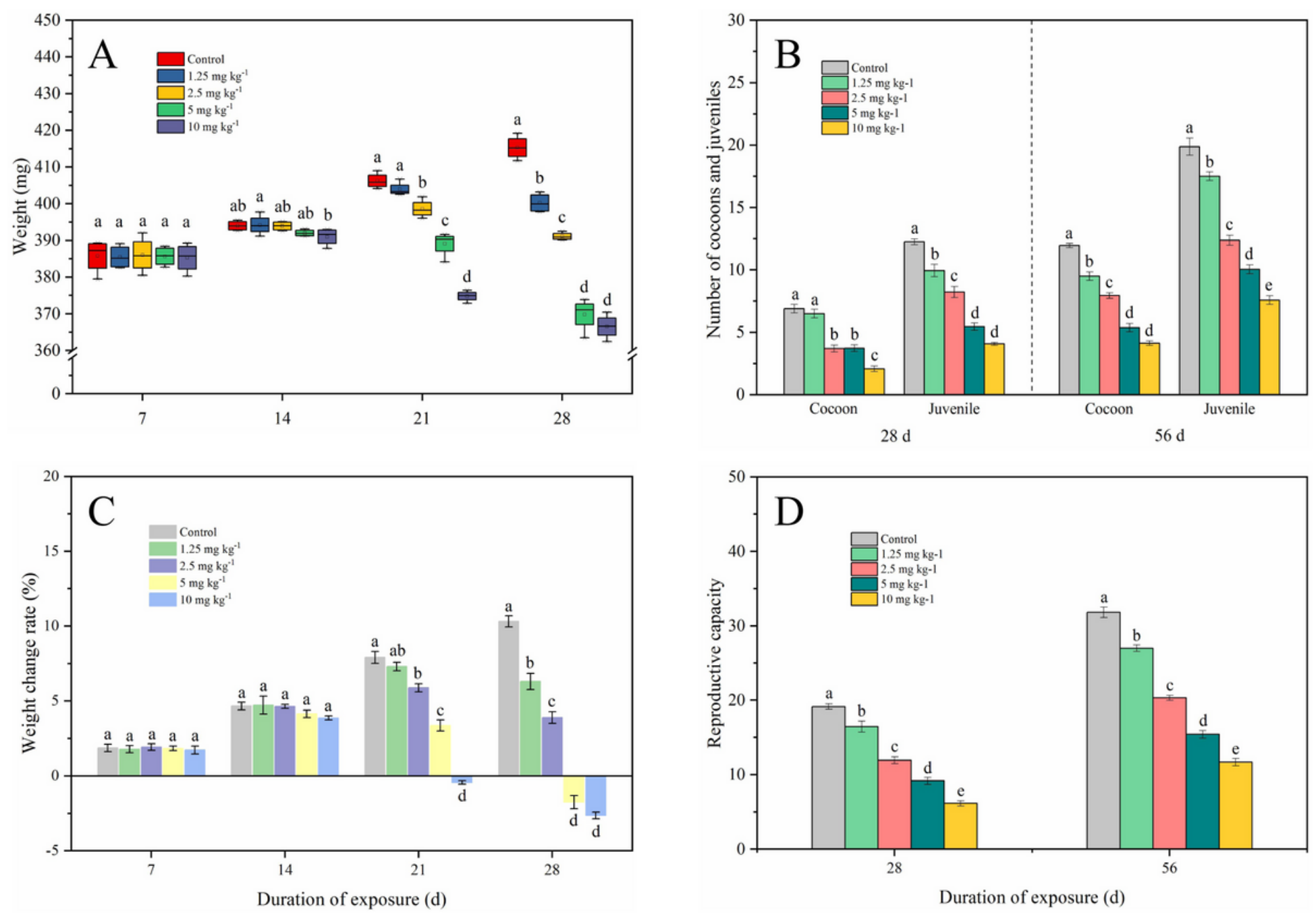

Figure 5

Weight changes ( $A$ and $C$ ), cocoon production and the number of juveniles ( $B$ and $D$ ) of Eisenia fetida upon exposure to phenanthrene. Different letters indicate significant differences $(P<0.05)$ among treatments. 


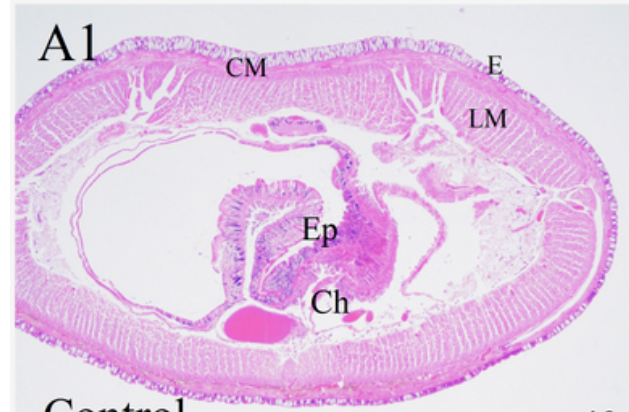

Control

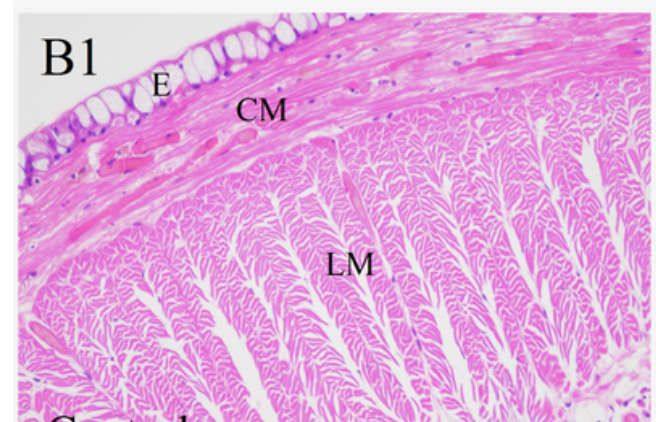

Control

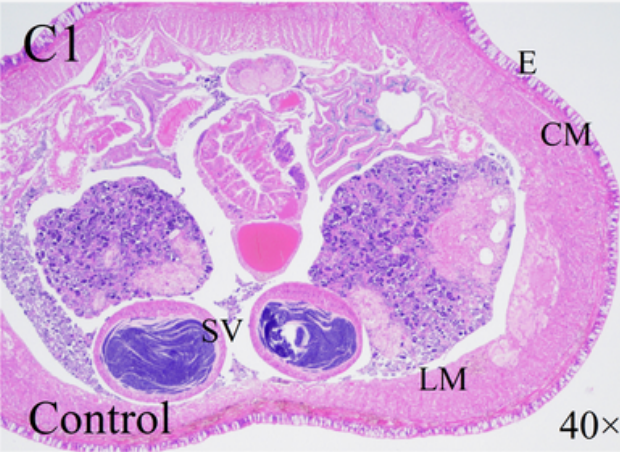

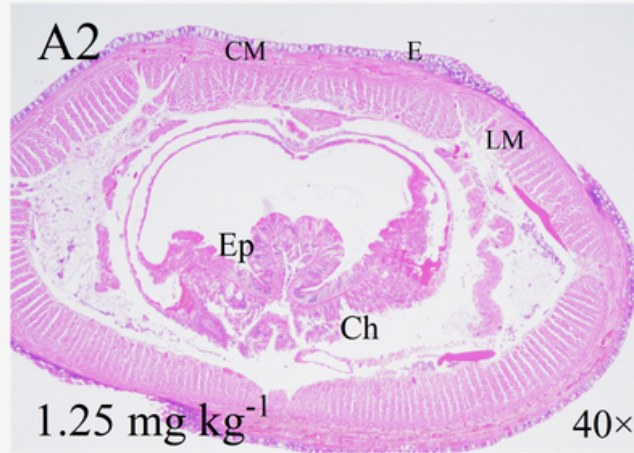
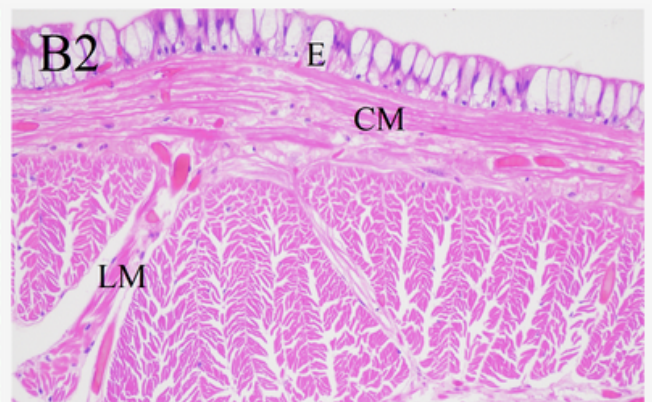

(St

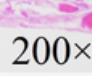

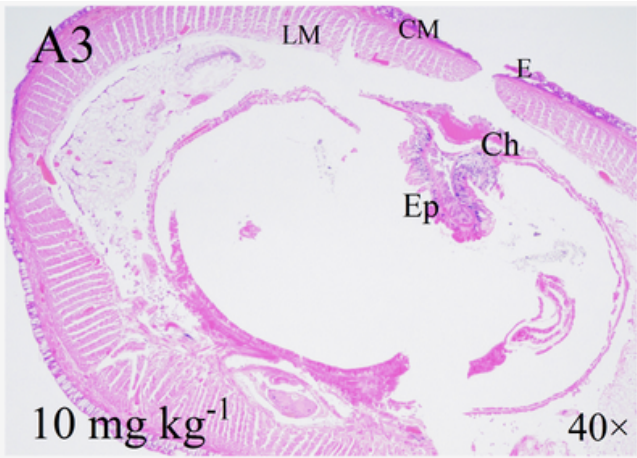
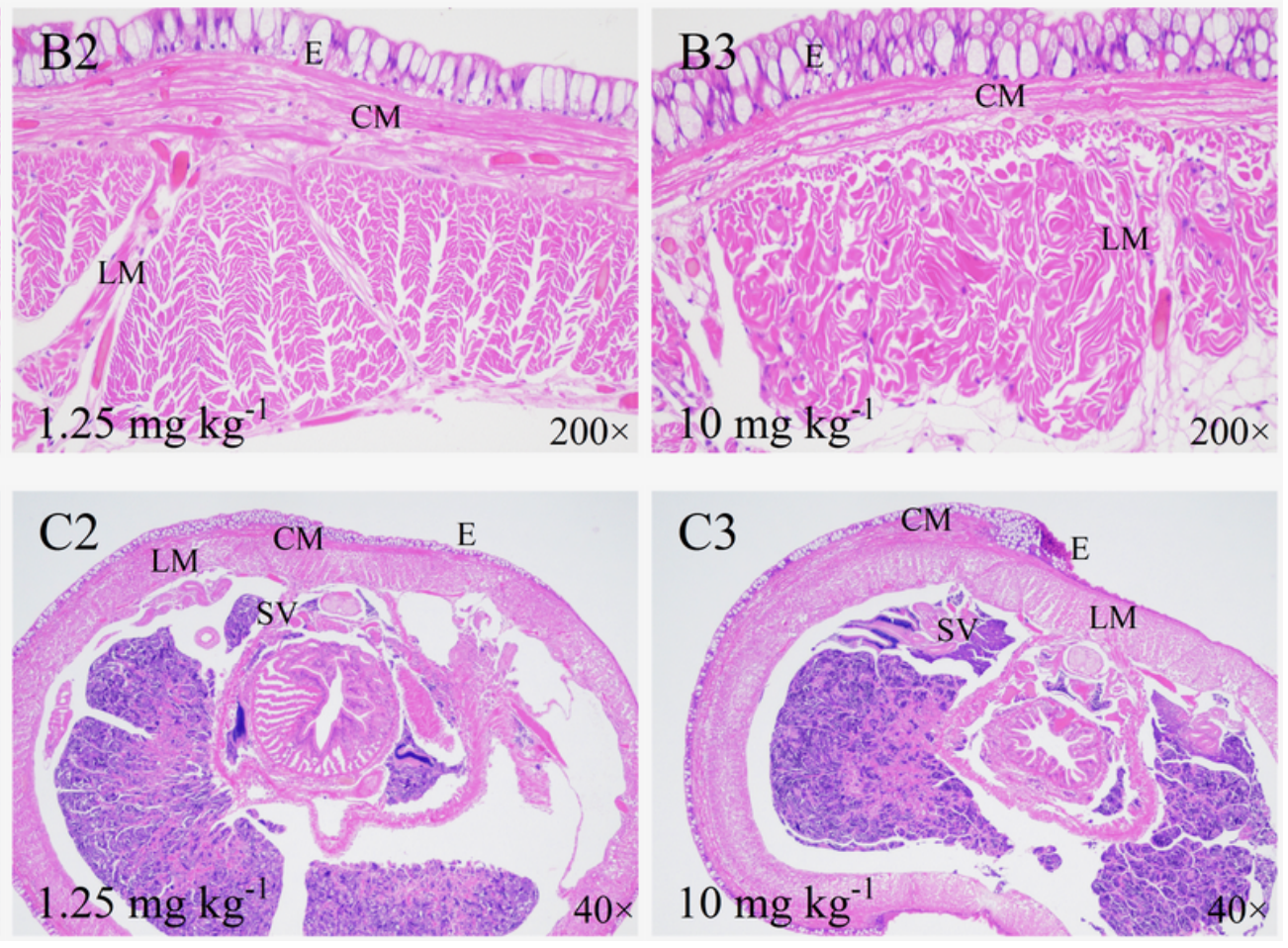

\section{Figure 6}

Histopathological changes of the intestinal tract (A), body wall (B), and seminal vesicles (C) of Eisenia fetida at $28 \mathrm{~d}$ after phenanthrene exposure. (E, CM, and LM represent the cuticular layer, circular muscle layer, and muscular layer, respectively; Ep and Ch denote the epithelial tissue and chloragogenous tissue of the Eisenia fetida intestine, respectively; SV denotes a seminal vesicle). 

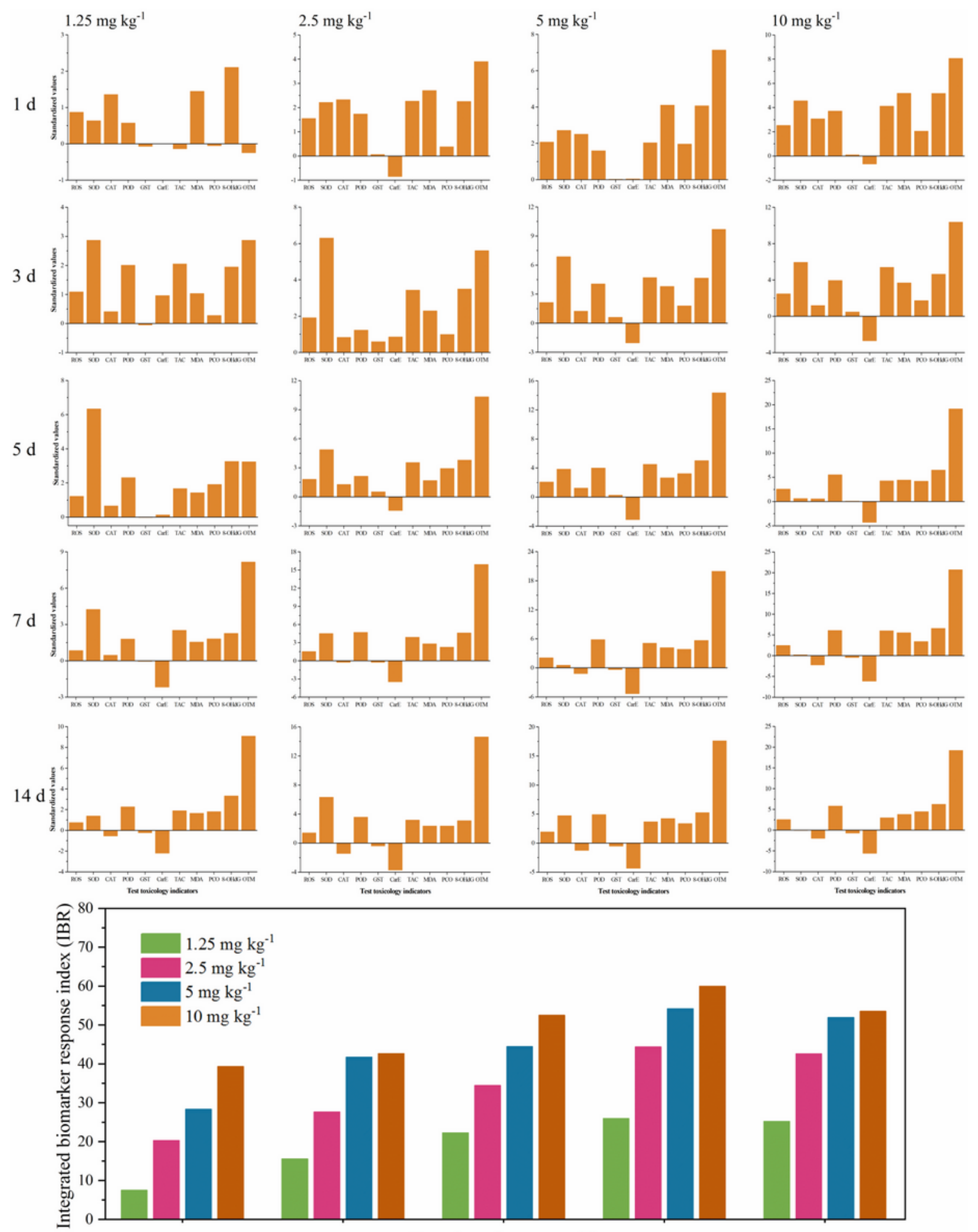

Duration of exposure (d)

\section{Figure 7}

Standardized values of all indicators and integrated biological response version 2 (IBRv2) values of Eisenia fetida after phenanthrene exposure on days 1, 3, 5, 7, and 14 .

\section{Supplementary Files}


This is a list of supplementary files associated with this preprint. Click to download.

- Supplementarymaterials.doc 